\title{
Aggregate and Individual Price Adjustment
}

Central to the Keynesian interpretation of economic fluctuations is the notion that prices and wages are rigid or "sticky," so that movements in aggregate demand, rather than being quickly reflected in price level movements, have instead long-lasting effects on output and economic activity. The word "rigidity" covers, in fact, two quite different notions. The first, which I shall refer to as real rigidity, is that real wages and markups of prices over wages respond little to shifts in demand. The second, which I shall refer to as nominal rigidity, is that nominal wages and prices respond slowly to changes in their determinants and in particular respond slowly to each other. Both real and nominal rigidities combine to lead to lasting effects of changes in aggregate demand on output.

The focus of the paper is on nominal rigidities. In earlier work on the joint behavior of prices, wages, and employment, I found that, contrary to prevailing wisdom, there appeared to be as much nominal price rigidity as nominal wage rigidity. ${ }^{1}$ This paper explores those findings further, looks at how interactions between individual prices lead to aggregate nominal price rigidity, and points out the macroeconomic implications of nominal price rigidity.

The first part reviews the role of real and nominal rigidities in the

I thank Anil Kashyap for excellent research assistance; Data Resources, Inc., for providing the data as well as information on their model; Julio Rotemberg, Jeff Woolridge, and members of the Brookings Panel for discussions and comments; and the National Science Foundation for financial assistance.

1. Olivier Jean Blanchard, "Empirical Structural Evidence on Wages, Prices and Employment," Working Paper 431 (Massachusetts Institute of Technology, September 1986). 
transmission of demand shocks to output. The second looks at the aggregate evidence on nominal rigidities. It confirms that the price level adjusts to changes in nominal wages no faster than wages adjust to the price level. That conclusion is robust to alternative assumptions regarding simultaneity and choice of variables.

The third and central part of the paper uses disaggregated prices to explore alternative explanations for the relatively slow adjustment of the price level to wages. It concludes that, in large part, slow adjustment of the price level comes from cumulation of small lags at the individual level. While individual price setters adjust their prices to wages and other input prices quickly, vertical and horizontal interactions between price decisions lead to a cumulation of those small lags and to slow aggregate price adjustment.

The final part draws the implications of the findings. Through crude simulations, it shows the respective roles of nominal price, nominal wage, and real rigidities in determining the dynamic effects of aggregate demand on output.

\section{Rigidities and Output Fluctuations}

To put this paper in perspective and show its relation to the general research agenda, it is best to start with a simple model of output, prices, and wages: ${ }^{2}$

$$
\begin{aligned}
& p=\mu p(-1)+(1-\mu) w+a y, \\
& w=\eta w(-1)+(1-\eta) p+b y, \\
& y=(m-p) .
\end{aligned}
$$

All variables are in logarithms, with $y, p, w$, and $m$ being output, the price level, the nominal wage, and the nominal money supply. No distinction is made between employment and output. Constants are ignored for notational simplicity.

2. Two recent surveys discuss these issues more formally and in more detail. See Olivier Jean Blanchard, “Why Does Money Affect Output?' in Benjamin Friedman and Frank Hahn, eds., Handbook of Monetary Economics (Amsterdam: North-Holland, forthcoming, 1988); and Julio Rotemberg, "The New Keynesian Microfoundations," in Stanley Fischer, ed., NBER Macroeconomics Annual, 1987 (MIT, forthcoming, 1987). 
The first equation is a price equation, giving the price level as a function of itself lagged, the nominal wage, and the level of output. The second is a wage equation, giving the nominal wage as a function of itself lagged, the price level, and the level of output. The third equation gives aggregate demand as a function of real money balances, ignoring all other factors.

In this model, the parameters $\mu$ or $\eta$ embody nominal rigidities. If $\mu$ is not zero, there is nominal price rigidity, and the price level does not adjust instantaneously to movements in the nominal wage. Similarly, if $\eta$ is not zero, there is nominal wage rigidity, and the nominal wage does not adjust instantaneously to movements in the price level. The parameters $a$ and $b$ in turn embody real rigidities. A low value of $a$ implies that firms require a small increase in the markup to increase output; a low value of $b$ that workers require a small increase in the real wage to supply more labor. ${ }^{3}$

Both nominal and real rigidities determine the dynamic effects of aggregate demand on output. As long as either $\mu$ or $\eta$ is not zero, movements in aggregate demand, such as a change in the nominal money supply in equation 3 , are not reflected in an instantaneous adjustment of the price level and thus have a lasting effect on output. The speed with which the price level adjusts to a change in nominal money is then a function of all four parameters, those reflecting nominal rigidities, $\mu$ and $\eta$, and those reflecting real rigidities, $a$ and $b$. Given $a$ and $b$, the stronger the nominal rigidities, that is, the larger $\mu$ and $\eta$, the lower the speed of adjustment of the price level and the longer lasting the real effects of changes in the nominal money supply. Given $\mu$ and $\eta$, in turn, the stronger the real rigidities, that is, the lower $a$ and $b$, the longer lasting the real effects of nominal money.

Under standard neoclassical assumptions, however, both $\mu$ and $\eta$ are equal to zero: movements in nominal variables, everything else the same, are fully and instantaneously reflected in other nominal variables.

3. In this model, absent nominal rigidities, there are no dynamics in either the wage or the price equation. This would not be the case in more general models: costs of adjustment of output or employment would lead, for example, to a dynamic relation between output and real wages in equation 1, quite apart from the presence or absence of nominal rigidities. More generally, there is no reason for the dynamic responses of prices to wages and employment to be the same in equation 1 , for the dynamic responses of wages to prices and employment to be the same in equation 2 . 
And under neoclassical assumptions, one would expect $a$ and $b$ to be positive and possibly quite large: under the interpretation of equation 1 as a competitive output supply equation, one would expect marginal cost to be increasing in output, and thus $a$ to be positive. Under the interpretation of equation 2 as a competitive labor supply equation, one would expect labor supply, barring intertemporal substitution effects, to be rather inelastic to the real wage, and thus $b$ to be large and positive. Thus recent research has focused on deviations from the neoclassical model that may explain why $a$ and $b$ may be small and why $\mu$ and $\eta$ may be different from zero.

Research on real rigidities in the goods market has focused on the behavior of imperfectly competitive firms. Under the assumption that goods markets are imperfectly competitive, equation 1 , with $\mu$ equal to zero, can no longer be interpreted as an output supply equation but describes instead the joint movement of markups and output in response to shifts in demand. Among the reasons suggested why markups may be insensitive to shifts in demand are that firms may carry excess capacity and have as a result flat marginal cost, and that firms may accept lower profit margins in booms, either to avoid price wars or because the elasticity of demand is higher then. ${ }^{4}$ Research on real rigidities in the labor market has explored various, largely unrelated, avenues. One topic has been the implications of bargaining between unions and firms, in which case equation 2-with $\eta$ equal to zero-describes the joint movement of employment and real wages in response to shifts in the demand for labor. The research has shown that under plausible assumptions about union preferences, technology, and bargaining, shifts in demand can lead to movements in employment with little change in the real wage and can thus generate an equation like equation 2 with a small value of $b .{ }^{5}$ Other research has shown that efficiency wage considerations can also lead to an equilibrium locus like equation 2 , with a small value of $b{ }^{6}$

4. For the former, see Robert E. Hall, "Market Structure and Macroeconomic Fluctuations," BPEA, 2:1986, pp. 285-321. For the latter, see Julio J. Rotemberg and Garth Saloner, "A Supergame-Theoretic Model of Price Wars during Booms," American Economic Review, vol. 76 (June 1986), pp. 390-407; Mark Bils, "Essays on the Cyclical Behavior of Price and Marginal Cost" (Ph.D. dissertation, MIT, 1985).

5. Ian M. McDonald and Robert M. Solow, "Wage Bargaining and Employment," American Economic Review, vol. 71 (December 1981), pp. 896-908.

6. See the surveys by Lawrence F. Katz, "Efficiency Wage Theories: A Partial Evaluation," in Stanley Fischer, ed., NBER Macroeconomics Annual, 1986 (MIT, 1986), 
Research on nominal rigidities has focused on why nominal wages and nominal prices may not adjust instantaneously to changes in their determinants-that is, on why $\mu$ and $\eta$ may not be zero. The initial impetus was given by Stanley Fischer, who showed the effects of nominal wage presetting, and by John Taylor, who showed how nominal wage presetting together with staggering of wage decisions could lead to substantial nominal inertia. ${ }^{7}$ More recently, research on both the static and dynamic effects of costs of changing prices has started providing more solid microfoundations for models like Taylor's. ${ }^{8}$ I shall review relevant aspects of this research below.

The next part of the paper estimates more general dynamic counterparts to equations 1 and 2 . Although I give estimates of $a$ and $b$ as well as of $\mu$ and $\eta$, the focus throughout is on nominal rigidities, on the distributed lag counterparts to $\mu$ and $\eta$. The main finding is that $\mu$ and $\eta$ are roughly of the same magnitude, that nominal wages and prices adjust to changes in each other at roughly the same speed. Given this finding, the third part of the paper examines the set of disaggregated price equations that underlies the aggregate price equation, in order to establish the source of the lags. The last part of the paper, using the estimated equations corresponding to equations 1 and 2 above, shows the respective roles of estimated $\mu, \eta, a$, and $b$ in determining the effects of aggregate demand on output.

\section{The Aggregate Evidence}

The empirical investigation starts with wage and price equations at a high level of aggregation. Such an aggregate analysis corresponds to the level at which most empirical research on inflation has been conducted.

pp. 235-76; and by Joseph E. Stiglitz, "Theories of Wage Rigidity," in James L. Butkiewicz, Kenneth J. Koford, and Jeffrey B. Miller, eds., Keynes' Economic Legacy (Praeger, 1986), pp. 153-206.

7. Stanley Fischer, "Long-Term Contracts, Rational Expectations, and the Optimal Money Supply Rule," Journal of Political Economy, vol. 85 (February 1977), pp. 191205; and John B. Taylor, "Staggered Wage Setting in a Macro Model," American Economic Review, vol. 69 (May 1979, Papers and Proceedings, 1978), pp. 108-13.

8. See Blanchard, "Why Does Money Affect Output?" and Rotemberg, "The New Keynesian Microfoundations." 


\section{SPECIFICATION OF THE PRICE AND WAGE EQUATIONS}

I assume that the price equation-and a parallel argument applies throughout to the wage equation-has the following structure:

$$
a(L) p=b(L) w+c(L) X+d(L) e,
$$

where $p$ and $w$ are the logarithms of the price level and the nominal wage, and $X$ is a vector of other variables that enter the equation. The variables $a(L), b(L), c(L)$, and $d(L)$ are lag polynomials, with the first elements of $a$ and $d$ equal to 1 by normalization; $e$ is a serially uncorrelated disturbance. Thus equation 4 gives the price as a function of itself lagged, current and lagged $w$ and $X$, and a serially uncorrelated disturbance term, $d(L) e$. While lag structures in equation 4 are most likely convolutions of expectational and other lag structures, I make no systematic attempt to decompose observed lag structures into those two components. Before that can be done, the shape of those lag structures must first be established.

Throughout the paper, I use monthly data. The effects of $w$ on $p$, and of $p$ on $w$ are fast; the effects of wages on prices are even faster for disaggregated prices. Monthly data would not necessarily be best if the focus were instead on the dynamic counterparts to $a$ and $b$ in the model sketched above: activity may well affect wages and prices slowly over time, and the use of lower frequency data, say, quarterly or annual, could filter out some undesirable noise.

My interest is in the dynamic response of $p$ to $w$, thus in the shape of the polynomial $s(L)=b(L) / a(L)$. The coefficients of $s(L)$ have a simple interpretation: $s_{i}$ gives the effect of a one-time increase in nominal wages of 1.0 at time $t$ on the price level at time $t+i$, everything else equal. In turn, the cumulative sum of coefficients $s_{i}$ from zero to $i$ gives the effect of a permanent increase in nominal wages of 1.0 at time $t$ on the price level at time $t+i$.

For the moment I ignore the simultaneity issue-that is, I assume that $e$ is uncorrelated at all leads and lags with $w$ and $X$. The polynomial $s(L)$ is identified in this case, although the lag polynomials in equation 4 cannot be separately identified: assuming $d(L)$ to be invertible and premultiplying both sides of equation 4 by $d(L)^{-1}$ gives:

$$
d(L)^{-1} a(L) p=d(L)^{-1} b(L) w+d(L)^{-1} c(L) X+e .
$$


Defining $a^{\prime}(L), b^{\prime}(L)$, and $c^{\prime}(L)$ appropriately gives

$$
a^{\prime}(L) p=b^{\prime}(L) w+c^{\prime}(L) X+e,
$$

where the first element of $a^{\prime}(L)$ is 1 . Simultaneity issues still being ignored, all lag polynomials in equation 5 are identified. Equation 5 can be estimated by ordinary least squares, simply allowing for enough lags on $p, w$, and $X$ to make the disturbance term be white noise. Noting that $b^{\prime}(L) / a^{\prime}(L)=b(L) / a(L), \mathrm{I}$ then recover $s(L)$ as the ratio of $b^{\prime}(L)$ to $a^{\prime}(L)$ in equation 5.

I now discuss what further restrictions should be imposed on the lag polynomials $a^{\prime}(L), b^{\prime}(L)$, and $c^{\prime}(L)$, and the issues associated with identification of the price and wage equations.

Homogeneity. If the price equation treated expectations explicitly, then, under a wide class of assumptions, one would expect that a doubling of all nominal variables, current, past, and expected, would lead to a doubling of prices. Put another way, one would expect the sum of the coefficients on all nominal variables in the equation to be equal to 1.0. I shall call this the homogeneity property. In equation 4 , however, expectations are already implicitly solved out and replaced by distributed lags of current and lagged variables, and the question arises of whether a similar condition applies to equation 4 and, in turn, to equation 5 . The answer is that if expectations of nominal variables are distributed lags of current and lagged nominal variables with coefficients summing to 1.0 , a similar condition will hold in equation 4 . This will, in turn, be consistent with rational expectations if, roughly stated, the process generating nominal variables contains a unit root. ${ }^{9}$ The intuition for this result is simple: rational expectations of nominal variables will depend on current and lagged nominal variables with coefficients summing to 1.0 , so that replacing expectations by current and lagged nominal variables will preserve the homogeneity property. There is little question that, in postwar U.S. data, nominal variables such as prices, wages, or money have not tended to return to any particular value and have had a unit root. Thus, in what follows, I impose a homogeneity property: the coefficients on lagged prices, current and lagged wages, and current and lagged values of nominal variables in $X$, if any, are constrained to sum to 1.0 .

9. A more formal statement and a proof are given in Blanchard, "Empirical Structural Evidence on Wages, Prices and Employment." 
First Differences or Levels? Preliminary estimation of the price and wage equations, equation 5 , in levels, with or without the homogeneity restriction, gave estimates such that the sum of coefficients on lagged prices was approximately equal to 1.0, and the sum of coefficients on each of the other right-hand side variables was nearly equal to zero. This suggests the presence of a common factor $(1-L)$ in $a^{\prime}(L), b^{\prime}(L)$, and $c^{\prime}(L)$ and suggests that in equation $4, d(L)$ can be rewritten as $(1-L)^{-1} d^{\prime}(L)$. Thus, I conclude that equation 4 has a disturbance term with a unit root. If equation 4 has a unit root and satisfies the homogeneity property, equation 5 can be estimated in first differences, imposing the homogeneity restriction. ${ }^{10}$ This is what I do below. ${ }^{11}$

Except for these two restrictions, I leave $a^{\prime}(L)$ and $b^{\prime}(L)$ unconstrained. This, together with the fact that I use monthly data that require long lag structures, leads to an estimated $s(L)$ that is the ratio of two estimated high-order lag polynomials and is neither necessarily smooth nor tightly estimated. Putting more structure, such as Almon polynomial constraints, or Bayesian priors for $a^{\prime}(L)$ and $b^{\prime}(L)$, may be useful for forecasting but would not be appropriate here, since part of the purpose of this part of the paper is to learn about the shape of $s(L)$.

Identification. There are two separate issues of identification. First, while the disturbance term $e$ in equation 5 is serially uncorrelated, it is not necessarily uncorrelated with lagged values of $w$ or $X$. If, for example, wages are set using advance information about prices that is not contained in past values of prices, wages, or variables in $X$, there may then be correlation between current $e$ and lagged wages. However, this is

10. A formal argument is as follows. Suppose that, for notational convenience, there are no nominal variables in $X$. Then if the disturbance term in equation 4 has a process with a unit root, $d(L)$ can be rewritten as $d(L)=(1-L)^{-1} d^{\prime}(L)$, so that:

$$
a(L) p=b(L) w+c(L) X+(1-L)^{-1} d^{\prime}(L) e .
$$

In addition, if equation 4 satisfies the homogeneity restriction, $a(1)-b(1)=0$. Premultiplying both sides by $d(L)^{-1}=(1-L) d^{\prime}(L)^{-1}$, and denoting first differences of any variable $x$ by $D x$, gives

$$
d^{\prime}(L)^{-1} a(L) D p=d^{\prime}(L)^{-1} b(L) D w+d^{\prime}(L)^{-1} c(L) D X+e,
$$

or defining $a^{\prime}(L), b^{\prime}(L)$, and $c^{\prime}(L)$ appropriately gives

$$
a^{\prime}(L) D p=b^{\prime}(L) D w+c^{\prime}(L) D X+e,
$$

where $a^{\prime}(1)-b^{\prime}(1)=0$.

11. When reporting the results of alternative specifications later, I give the results of estimation of the basic specification without the homogeneity restriction. 
unlikely to be a serious problem, except perhaps when estimating disaggregated price equations, when prices are at the beginning of the chain of production and depend in large part on prices of inputs traded in spot markets.

The second issue is contemporaneous correlation between $w$ or $X$ and $e$. Focusing, for example, on the correlation between wages and $e$ in the price equation, I can derive plausible upper and lower bounds for the current effect of wages on prices, given $X$. If I assume that the current effects of wages on prices and of prices on wages, given $X$, are nonnegative and that the correlation between disturbances in the price and wage equations is also nonnegative, the coefficient on current wages in the price equation (and the coefficient on current prices in the wage equation) obtained by ordinary least squares will have a nonnegative bias. Thus a lower bound of zero on the current effects of wages on prices is obtained by leaving current wages out of equation 5 , and an upper bound is obtained by leaving current wages in and using again OLS. A similar argument holds, for example, for the price of crude materials, if it is included in the vector $X$. I present results for two cases below, first leaving all current values of $w$ and $X$ in, then leaving them out. ${ }^{12}$ Given the use of monthly data, the alternative treatments of simultaneity turn out to make no substantive difference.

\section{THE BASIC SPECIFICATION AND RESULTS OF ESTIMATION}

The basic specification was chosen on the basis of my previous work and that of others. ${ }^{13}$ Alternative specifications that examine the robust-

12. One can think of cases where the correlation between disturbances to the wage and the price equation, say $e_{w}$ and $e_{p}$, will be negative. If, for example, wages are set by bargaining between firms and workers, an unexpected positive productivity shock may lead firms both to decrease prices and to pay higher wages. In this case, there would be a negative correlation between $e_{p}$ and $e_{w}$, and the true coefficients on $p$ and $w$ in the wage and the price equations, respectively, could lie outside of the lower and upper bounds derived in the text. The implicit assumption in the text is therefore that there are sufficiently many other shocks to wages and to prices that this effect is not quantitatively important. Further progress would require using a more explicitly structural approach to the wage equation.

13. Robert J. Gordon and Stephen R. King, "The Output Cost of Disinflation in Traditional and Vector Autoregressive Models," BPEA, 1:1982, pp. 205-42; and Robert J. Gordon, "Understanding Inflation in the 1980s, " BPEA, 1:1985, pp. 263-99. 
ness of the estimated $s(L)$ to relaxation of the homogeneity restriction and alternative choices of variables and of sample are considered below.

Consistent with the discussion above, all variables in the price and wage equations, except the obvious ones, such as dummies and the time trend, are in first differences of logarithms; the homogeneity restriction is imposed throughout; results are presented for estimation both leaving all current values of the right-hand side variables in and leaving all of them out, except again for dummies and time trend. Because the appropriate wage indexes did not exist until 1964, the monthly sample used throughout starts in January 1965 and ends in May 1986.

Preliminary tests of lag length indicated that ten lags for each variable were sufficient to characterize the dynamics of both aggregate price and wage equations. Thus, all regressions assume a lag length of ten months. This is probably an overparameterization, and shorter lag lengths would be appropriate for some of the variables. I have not experimented with different lag lengths for different variables.

The price equation explains the personal consumption deflator $(p c)$. The correlation between the first differences of manufacturing wages and nonmanufacturing wages is only 0.46 . To avoid potential aggregation bias involved in the use of an aggregate wage index when wages do not move together, an issue discussed at more length in the next part of the paper, I allow both manufacturing and nonmanufacturing wages to appear as separate regressors. Thus the two wages included in the price equation are the hourly earnings index for manufacturing $(\mathrm{wm})$ and the hourly earnings index for private nonfarm nonmanufacturing $(w n)$. Both wages are adjusted for overtime and interindustry shifts.

The set of $X$ variables includes, in addition to a time trend and a set of additive seasonal dummies, aggregate private nonfarm employment $(e t)$, the producer price index for crude materials $(p 1)$, and a set of six wage-price control dummies for 1971-74, corresponding to the two freezes, phases one to three, and the two months following decontrol. ${ }^{14}$ These dummies have been important in past work and are here as well.

Because the price equation includes two different wages, there are two separate wage equations, one for the manufacturing wage $(\mathrm{wm})$ and

14. As both the price and wage equations are estimated in first differences, the time trend captures deterministic trends in the rates of change of prices and wages, not in their levels. 
one for the nonmanufacturing wage ( $w n)$. In both cases, the price is the personal consumption deflator $(p c)$. The set of $X$ variables is the same as for the price equation, except for the absence of the producer price index for crude materials ( $p 1)$, which had consistently small and insignificant effects in preliminary regressions.

Results are presented in table 1 for the price equation, in tables $2 \mathrm{a}$ and $2 \mathrm{~b}$ for the wage equations. Each table contains two sets of results. The results of estimation allowing for current effects of the right-hand side variables are reported in the left part of the table; the results of estimation not allowing for such effects, in the right part.

The first panel of each table presents the dynamic effects of a permanent increase of 1.0 at time 1 in a given right-hand side variable on the variable explained in the regression. In table 1 , for example, the first column gives the effect of a permanent increase in employment on the price level, everything else the same. This dynamic effect is computed as follows: let $b_{e}{ }^{\prime}(L)$ and $a^{\prime}(L)$ be the estimated distributed lag on employment and on prices in the price equation. The dynamic effect is then the cumulative sum of the coefficients of the polynomial $b_{e}{ }^{\prime}(L) / a^{\prime}(L)$. All dynamic effects in the tables are computed in similar fashion. ${ }^{15}$ There is enough collinearity between the two wages in the price equation that the response to each wage is estimated imprecisely (the one standard deviation band for the response of the price to each wage is close to $+0.3,-0.3$ ); the response to a joint increase of 1.0 in both wages, however, is estimated precisely and is reported in the last column for each set of results. The dynamic responses of the price to a joint increase in wages and of each wage to an increase in the price are also plotted, together with one standard deviation bands obtained by Monte Carlo simulations, in figures 1 and 2.

The next two lines of the tables give the significance levels associated with the restrictions that the sets and sums of coefficients on specific right-hand side variables are equal to zero. A low value of the significance level in the first line indicates that the set of coefficients on a given variable is significantly different from zero. A low value of the signifi-

15. This is only a convenient and intuitive way of presenting the information contained in the estimated lag structures. It is not, however, a sample experiment, in the way impulse responses in vector autoregressive systems would be. There was no such thing in the sample as a "permanent increase in variable $x$, everything else the same." 










Table 2a. The Manufacturing Wage Equation, January 1965-May 1986a

Cumulative effects on the manufacturing wage of a

Time period, significance level, and summary statistic

\begin{tabular}{cccccc}
\cline { 1 - 1 } \cline { 5 - 6 } Month & Employment & $\begin{array}{c}\text { Consumer } \\
\text { prices }\end{array}$ & & Employment & $\begin{array}{c}\text { Consumer } \\
\text { prices }\end{array}$ \\
\hline 1 & -0.01 & 0.09 & 0.00 & 0.00 \\
2 & -0.08 & 0.17 & 0.00 & 0.10 \\
3 & -0.12 & 0.25 & -0.04 & 0.19 \\
4 & -0.10 & 0.32 & -0.05 & 0.26 \\
5 & -0.09 & 0.43 & & -0.03 & 0.37 \\
6 & 0.03 & 0.36 & 0.11 & 0.32 \\
9 & 0.03 & 0.73 & 0.10 & 0.66 \\
12 & 0.05 & 0.80 & 0.13 & 0.79 \\
24 & 0.10 & 0.97 & 0.17 & 0.97 \\
Long-run & 0.10 & 1.00 & 0.18 & 1.00
\end{tabular}

Significance level ${ }^{\mathrm{b}}$

Coefficient ${ }^{c}$

0.08

0.001

0.16

0.001

Sum of coefficients ${ }^{\mathrm{d}}$

0.47

$0.4 \times 10^{-5}$

0.18

$0.3 \times 10^{-5}$

Summary statistic

Number of observations

Current effects allowed

Current effects excluded

Number of variables

Significance level ${ }^{\mathrm{b}}$

Homogeneitye

0.54

0.68

Control dummies ${ }^{\mathrm{f}}$

0.0008

0.001

Sum of control dummies ${ }^{\mathrm{g}}$

0.61

0.54

Source: Same as table 1.

a. Monthly data. All variables are expressed as differences in logarithms. Dependent variable is the AHE index in manufacturing, $w m$, adjusted for overtime and interindustry shifts. Independent variables are private nonfarm employment, $e t$, and the personal consumption deflator, $p c$. Control dummies are as defined in note a, table1.

b. See note b, table 1 .

c. See note c, table 1 .

d. See note d, table 1 .

e. See note e, table 1 .

f. See note $\mathrm{f}$, table 1 .

g. See note $\mathrm{g}$, table 1

cance level on the second line indicates that the sum of coefficients on a given variable is significantly different from zero.

Finally, each table reports basic summary statistics including significance levels associated with the homogeneity restriction. The significance level indicates the probability of observing the actual outcome if the restriction held: a low value implies likely rejection. Significance levels are also reported for restrictions that the set and sum of coefficients on wage-price control dummies are equal to zero. 
Table 2b. The Nonmanufacturing Wage Equation, January 1965-May 1986 $^{\text {a }}$

\begin{tabular}{|c|c|c|c|c|}
\hline \multirow{4}{*}{$\begin{array}{c}\text { Time period, } \\
\text { significance level, } \\
\text { and summary statistic }\end{array}$} & \multicolumn{4}{|c|}{$\begin{array}{l}\text { Cumulative effects on the nonmanufacturing wage of a } \\
\text { permanent increase of } 1.0 \text { in other variables at time } 1\end{array}$} \\
\hline & \multicolumn{2}{|c|}{ Current effects allowed } & \multicolumn{2}{|c|}{ Current effects excluded } \\
\hline & \multirow[b]{2}{*}{ Employment } & \multirow{2}{*}{$\begin{array}{l}\text { Consumer } \\
\text { prices }\end{array}$} & \multirow[b]{2}{*}{ Employment } & \multirow{2}{*}{$\begin{array}{l}\text { Consumer } \\
\text { prices }\end{array}$} \\
\hline & & & & \\
\hline 1 & 0.19 & 0.02 & 0.00 & 0.00 \\
\hline 2 & 0.18 & 0.23 & 0.04 & 0.22 \\
\hline 3 & 0.17 & 0.15 & 0.07 & 0.17 \\
\hline 4 & 0.20 & 0.43 & 0.08 & 0.40 \\
\hline 5 & 0.17 & 0.35 & 0.07 & 0.32 \\
\hline 6 & 0.17 & 0.39 & 0.05 & 0.35 \\
\hline 9 & 0.14 & 0.55 & 0.02 & 0.55 \\
\hline 12 & 0.19 & 0.70 & 0.07 & 0.69 \\
\hline 24 & 0.22 & 0.91 & 0.09 & 0.90 \\
\hline Long-run & 0.24 & 1.00 & 0.10 & 1.00 \\
\hline \multicolumn{5}{|l|}{ Significance level ${ }^{\mathrm{b}}$} \\
\hline Coefficient $^{c}$ & 0.71 & 0.02 & 0.99 & 0.02 \\
\hline Sum of coefficients ${ }^{d}$ & 0.31 & 0.001 & 0.68 & 0.003 \\
\hline Summary statistic & \multicolumn{2}{|c|}{ Current effects allowed } & \multicolumn{2}{|c|}{ Current effects excluded } \\
\hline Number of observations & \multirow{2}{*}{\multicolumn{2}{|c|}{$\begin{array}{r}257 \\
51\end{array}$}} & \multirow{2}{*}{\multicolumn{2}{|c|}{$\begin{array}{r}257 \\
51\end{array}$}} \\
\hline Number of variables & & & & \\
\hline $\bar{R}^{2}$ & \multicolumn{2}{|c|}{0.65} & \multicolumn{2}{|c|}{0.55} \\
\hline \multicolumn{5}{|l|}{ Significance level ${ }^{\mathrm{b}}$} \\
\hline Homogeneity ${ }^{e}$ & \multicolumn{2}{|c|}{0.004} & \multicolumn{2}{|c|}{0.002} \\
\hline Control dummies ${ }^{\mathrm{f}}$ & \multicolumn{2}{|c|}{0.12} & \multicolumn{2}{|c|}{0.12} \\
\hline Sum of control dummies $\mathrm{g}$ & \multicolumn{2}{|c|}{0.84} & \multicolumn{2}{|c|}{0.93} \\
\hline
\end{tabular}

Source: Same as table 1.

a. Monthly data. All variables are expressed as differences in logarithms. Dependent variable is the AHE index in nonmanufacturing industries, $w n$, adjusted for overtime and interindustry shifts. Independent variables are as defined in table $2 \mathrm{a}$, note $\mathrm{a}$, and control dummies are as defined in note $\mathrm{a}$, table 1 .

b. See note $b$, table 1 .

c. See note c, table 1 .

d. See note d, table 1 .

e. See note e, table 1 .

f. See note $f$, table 1 .

g. See note $\mathrm{g}$, table 1 .

In describing the results here and later in the paper, I shall emphasize the findings on nominal rigidities, the robustness of which to alternative specifications I have checked thoroughly. Because the equations also give estimates of real rigidities, I shall also report them, though, for reasons explained earlier, particularly the use of monthly data, I do not have the same degree of confidence in those estimates.

Tables $1,2 \mathrm{a}$, and $2 \mathrm{~b}$ show two main findings on nominal rigidities. The first is that the adjustments of both prices to wages and wages to 
Figure 1. Dynamic Response of Prices to Wages ${ }^{\mathrm{a}}$

Change in logarithms

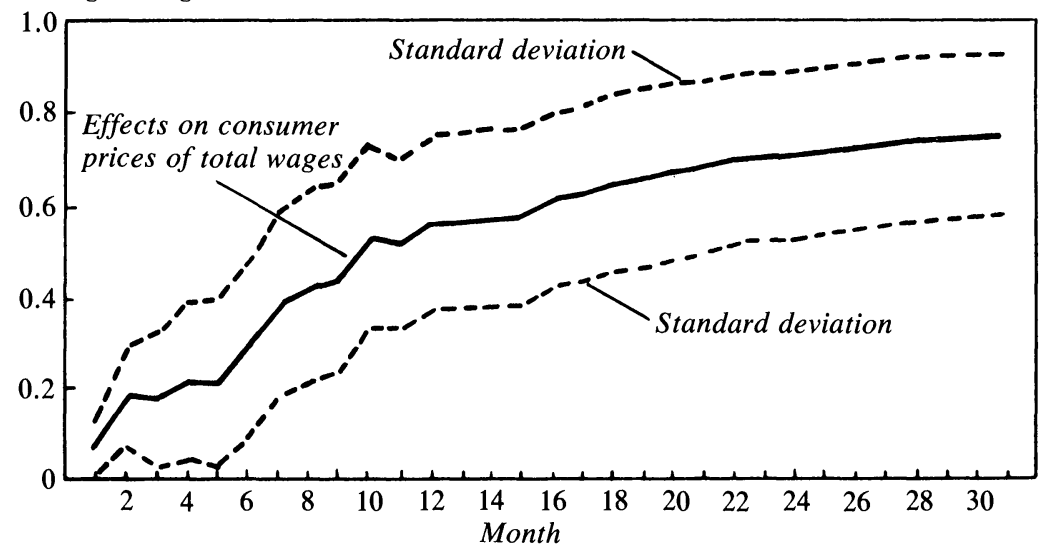

Source: Author's calculations based on results in table 1 .

a. Measure of the cumulative effects on consumer prices of a permanent increase of 1.0 at time 1 in total wages (solid line) and one standard deviation bands (dashed lines).

prices are relatively fast: in all cases the adjustment is between 60 percent and 80 percent complete within a year. ${ }^{16}$ The second and main one is that the speed of adjustment is roughly the same for wages to prices and for prices to wages. When current effects are allowed, the adjustment of wages to prices and of prices to wages is one-third complete after six months, two-thirds complete after a year. When current effects are not allowed, the adjustment of prices to wages is slower while the adjustment of wages to prices is roughly unaffected. Figures 1 and 2, which give one standard deviation confidence bands for those dynamic adjustments, show that it is impossible to say categorically which adjustment is faster, but the figures strongly refute the picture of fast price and slow wage adjustment.

The primary finding on real rigidities is that there is no strong effect of employment, which is the variable used in the basic specification to measure activity, on either the price or the wage equations. While the long-run effect of employment is, as one would expect, positive in all three equations, there is no strong evidence that either the set or the sum

16. The implication, as was shown in the simple model in the first section, is not that the effects of aggregate demand on output are largely over within a year. This depends on both nominal and real rigidities, on the speed of adjustment of prices and wages to each other, and on the effect of activity variables. I return to those issues in the last part of the paper. 
Figure 2. Dynamic Response of Manufacturing and Nonmanufacturing Wages to Prices ${ }^{\mathrm{a}}$

Change in logarithms

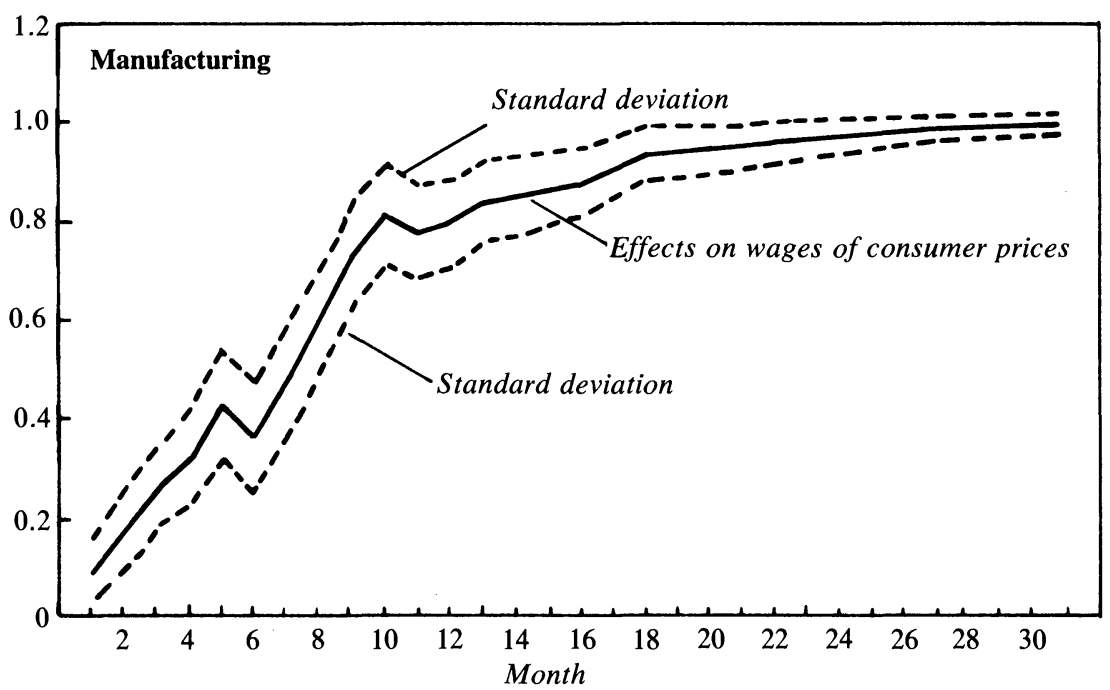

Change in logarithms

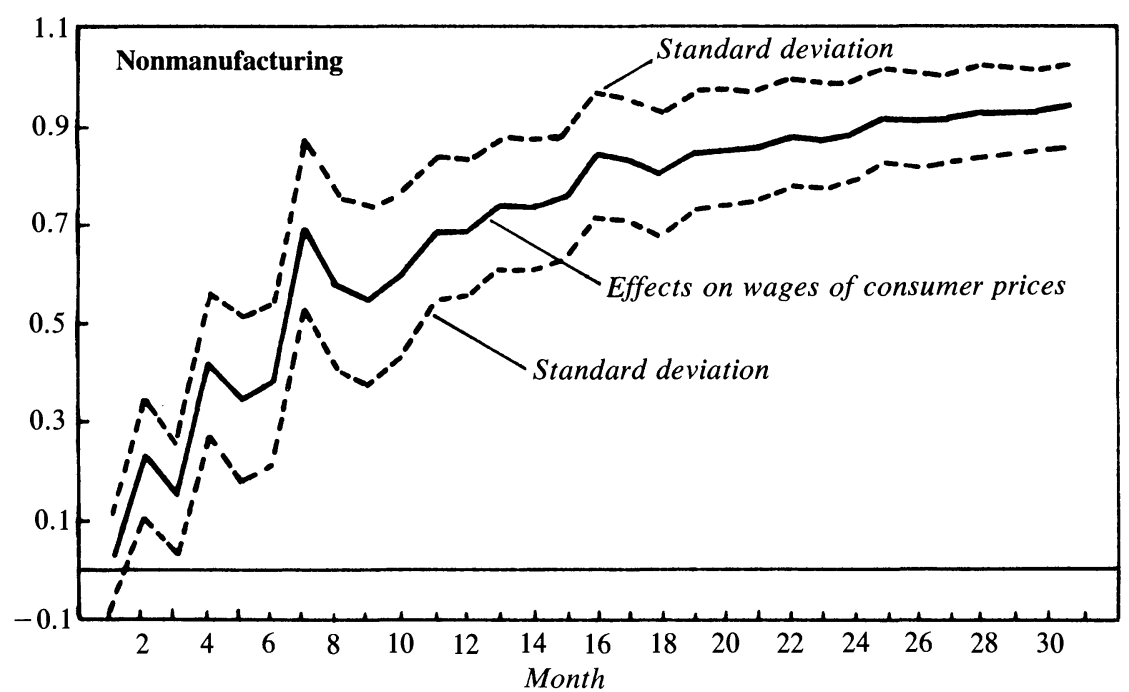

Source: Author's calculations based on results in tables $2 \mathrm{a}$ and $2 \mathrm{~b}$.

a. Measures of the cumulative effects on manufacturing and nonmanufacturing wages of a permanent increase of 1.0 at time 1 in consumer prices (solid line) and one standard deviation bands (dashed lines). 


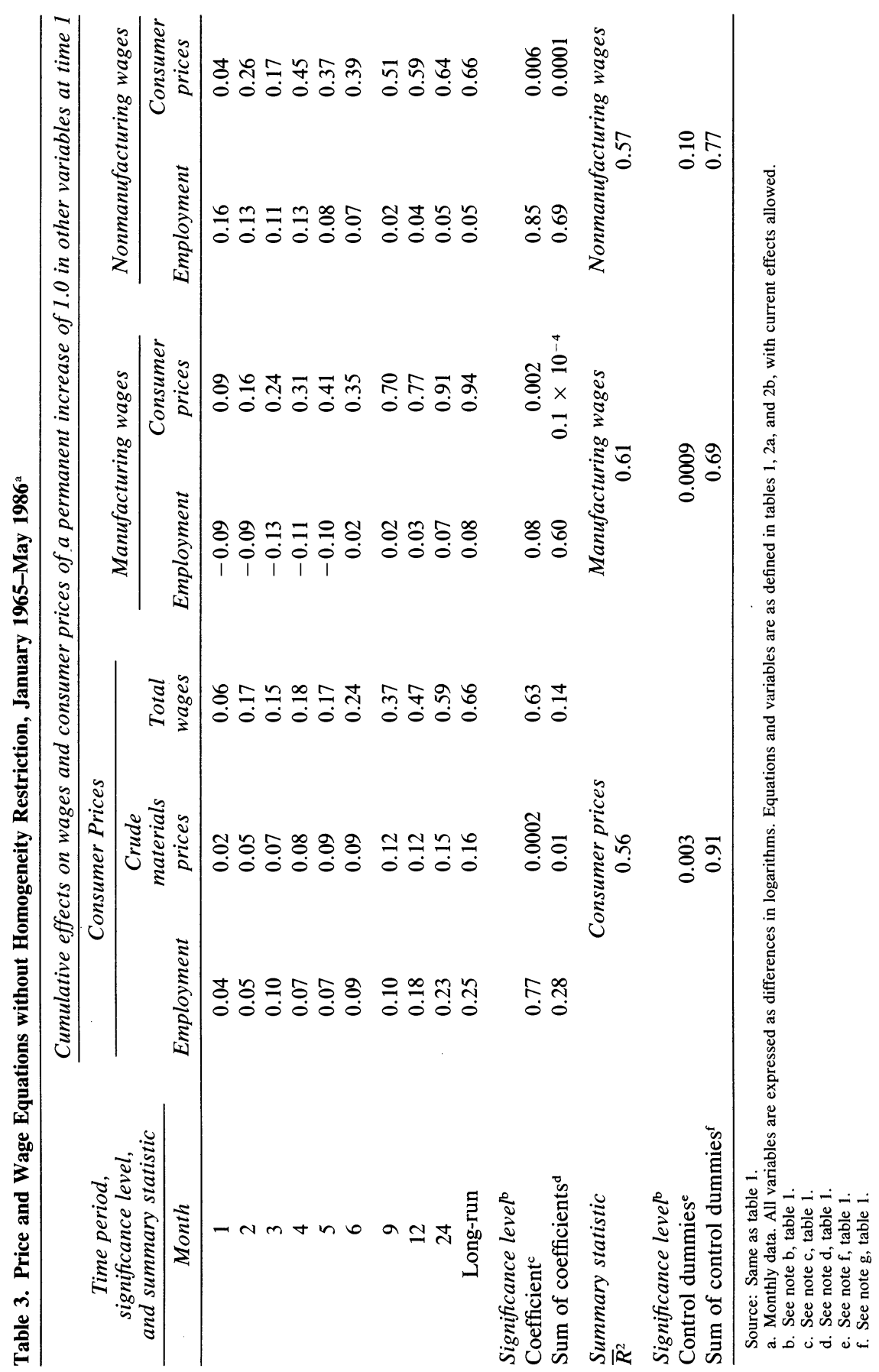


of coefficients on employment is significantly different from zero in any of the equations. This finding is at odds with the standard view that there is a strong effect of activity, measured by unemployment or an output gap measure, on wages. More evidence on that aspect of the results is given below, when I look at the effects of choosing alternative activity variables.

\section{ALTERNATIVE SPECIFICATIONS}

When the basic specification for both price and wage equations is modified, the findings about relative speeds are robust, except in two cases. The first is the choice of the wage variable: some alternative wage variables lead to slower estimated adjustment of prices to wages, while leaving the speed of wage adjustment unchanged. The other is the choice of the sample: there is evidence of subsample instability, with slower adjustment of both prices and wages later in the sample.

Removing the Homogeneity Restriction. Results of estimation of the basic specification when the homogeneity restriction is not imposed are given in table 3 , where, to save space, only results of estimation allowing for current effects of the right-hand side variables are reported.

Relaxing the homogeneity restriction makes little difference to the price and manufacturing wage equations. The estimated long-run elasticities of the price and of the manufacturing wage to nominal variables, which are constrained to 1.0 under the homogeneity restriction, are equal to 0.82 and 0.94 , respectively. It makes more of a difference to the equation for the nonmanufacturing wage, which has an estimated longrun elasticity of the wage with respect to the price level of only 0.66 .

This finding does not substantively affect the previous conclusion about nominal rigidities. If anything, it reinforces the conclusion that the price level adjusts to wages more slowly than wages do to the price level. The speed of adjustment of the nonmanufacturing wage to a change in the price level is now faster, with more than half of the long-run adjustment complete within six months.

Relaxing the homogeneity restriction also has little bearing on the effect of employment on prices or wages. Coefficients on employment, either as a set or as a sum, remain statistically insignificant in all three equations.

Alternative Activity Variables. The basic specification uses total employment as the activity variable. Other variables that are available 
monthly and have been used either alone or in combination in previous studies of wages and prices include manufacturing employment, the unemployment rate, the index of industrial production, and capacity utilization in manufacturing. I have tried these variables alone or in combination, with two general findings. The first is that estimated dynamic responses of prices and wages to each other are roughly invariant to the specific activity variable-or variables-used in estimation. The second is that, as was the case for employment, activity variables are usually insignificant. The findings from two specifications are worth mentioning.

First, the joint inclusion of manufacturing employment and production, which allows for both productivity and output effects, does not improve the fit in the price equation. ${ }^{17}$

The second finding concerns the Phillips curve specification of the wage equation. The standard Phillips curve, with or without the constraint that the long-run effect of price inflation on wage inflation be equal to 1.0, is not a special case of the specification used in the paper. The Phillips curve, in contrast to equation 2 or its more general dynamic counterpart, equation 4 , does not imply a long-run relation between the level of the real wage and the level of unemployment, but rather a relation between the rate of change of the real wage and the level of unemployment. The question arises whether a Phillips curve-like specification leads to different results. Table $4 \mathrm{a}$ reports the results of estimation of two specifications for the manufacturing wage, both allowing for current effects of the right-hand side variables. The first is similar to the basic specification, with the rate of change in employment replaced by the change in the unemployment rate. The second replaces the change in the unemployment rate by the level of the unemployment rate. It therefore regresses the rate of wage inflation on a distributed lag of itself, a distributed lag of price inflation, and a distributed lag of unemployment and is similar in specification to the Phillips curve. Table $4 \mathrm{~b}$ does the same for the nonmanufacturing wage.

17. When the price equation is estimated in levels, the sum of coefficients on all righthand side variables remains very close to zero, except for the sum of coefficients on lagged prices, which is close to 1.0. The suggestion is that the underlying disturbance term still has a unit root. This, in turn, implies either that these terms do not capture permanent changes in productivity or that the source of nonstationarity of the disturbance term in the price equation is not productivity growth. 
Table 4a. Manufacturing Wage Equation with Current Effects Allowed Using Unemployment as the Activity Variable, January 1965-May 1986 $^{\mathrm{a}}$

\begin{tabular}{|c|c|c|c|c|}
\hline \multirow{3}{*}{$\begin{array}{c}\text { Time period and } \\
\text { significance level }\end{array}$} & \multicolumn{4}{|c|}{$\begin{array}{l}\text { Cumulative effects on the manufacturing wage of a } \\
\text { permanent increase of } 1.0 \text { in other variables at time } 1\end{array}$} \\
\hline & \multicolumn{2}{|c|}{ Equation 1} & \multicolumn{2}{|c|}{ Equation 2} \\
\hline & $\begin{array}{l}\text { Unemploy- } \\
\text { ment }\end{array}$ & $\begin{array}{l}\text { Consumer } \\
\text { prices }\end{array}$ & $\begin{array}{l}\text { Unemploy- } \\
\text { ment }\end{array}$ & $\begin{array}{l}\text { Consumer } \\
\text { prices }\end{array}$ \\
\hline 1 & -0.09 & 0.10 & -0.09 & 0.10 \\
\hline 2 & 0.01 & 0.21 & 0.01 & 0.21 \\
\hline 3 & 0.15 & 0.27 & 0.14 & 0.27 \\
\hline 4 & 0.16 & 0.37 & 0.15 & 0.36 \\
\hline 5 & 0.13 & 0.51 & 0.12 & 0.50 \\
\hline 6 & 0.18 & 0.43 & 0.17 & 0.43 \\
\hline 9 & -0.03 & 0.79 & -0.06 & 0.79 \\
\hline 12 & -0.02 & 0.83 & -0.02 & 0.83 \\
\hline 24 & -0.06 & 0.97 & -0.08 & 0.97 \\
\hline 36 & -0.06 & 1.00 & -0.10 & 0.99 \\
\hline Long-run & -0.06 & 1.00 & $\ldots{ }^{\mathrm{b}}$ & 1.00 \\
\hline \multicolumn{5}{|l|}{ Significance level } \\
\hline Coefficient $^{d}$ & 0.41 & 0.0007 & 0.46 & 0.001 \\
\hline \multirow[t]{2}{*}{ Sum of coefficients ${ }^{e}$} & 0.67 & $0.3 \times 10^{-5}$ & 0.82 & $0.4 \times 10^{-5}$ \\
\hline & \multicolumn{2}{|c|}{ Equation 1} & \multicolumn{2}{|c|}{ Equation 2} \\
\hline \multicolumn{5}{|l|}{ Significance level ${ }^{\mathrm{c}}$} \\
\hline Homogeneity ${ }^{f}$ & \multicolumn{2}{|c|}{0.54} & \multicolumn{2}{|c|}{0.49} \\
\hline Control dummies & \multicolumn{2}{|c|}{0.0002} & \multicolumn{2}{|c|}{0.0002} \\
\hline Sum of control dummies ${ }^{h}$ & \multicolumn{2}{|c|}{0.57} & \multicolumn{2}{|c|}{0.57} \\
\hline
\end{tabular}

Source: Author's calculations. See text description.

a. Monthly data. All variables are expressed as differences in logarithms; the unemployment rate in equation 2 is expressed as a level. Dependent variable is the AHE index in manufacturing, $w m$; independent variables are the unemployment rate, $u$, and the personal consumption deflator, $p c$. Control dummies are defined in note a, table 1 .

b. Since the equation specifies a relation between the rate of change of wages and the level of unemployment, and since the sum of coefficients on unemployment is not equal to zero, the long-run effect of unemployment on the level of wages is infinite. As the table shows, it grows, however, very slowly through time.

c. See note $b$, table 1 .

d. See note c, table 1 .

e. See note d, table 1 .

f. See note e, table 1 .

g. See note $f$, table 1 .

h. See note $\mathrm{g}$, table 1 .

Tables $4 \mathrm{a}$ and $4 \mathrm{~b}$ contain three main findings. The first is that the speeds of adjustment of wages to prices are similar to those presented in tables $2 \mathrm{a}$ and $2 \mathrm{~b}$ : if the focus is on nominal rigidities, the choice of activity variables is irrelevant. The second is that the dynamic effects of unemployment on wages are nearly identical for the first thirty months in the regressions using the level or the change in unemployment: put another way, when unemployment is entered in level, the data very nearly satisfy 
Table 4b. Nonmanufacturing Wage Equation with Current Effects Allowed Using Unemployment as the Activity Variable, January 1965-May 1986 $^{\mathrm{a}}$

\begin{tabular}{|c|c|c|c|c|}
\hline \multirow{2}{*}{$\begin{array}{l}\text { Time period and } \\
\text { significance level }\end{array}$} & \multicolumn{4}{|c|}{$\begin{array}{c}\text { Cumulative effects on the nonmanufacturing wage } \\
\text { of a permanent increase of } 1.0 \text { in other variables } \\
\text { at time } 1\end{array}$} \\
\hline & \multicolumn{2}{|c|}{ Equation 1} & \multicolumn{2}{|c|}{ Equation 2} \\
\hline$\frac{\text { significance level }}{\text { Month }}$ & $\begin{array}{l}\text { Unemploy- } \\
\text { ment }\end{array}$ & $\begin{array}{l}\text { Consumer } \\
\text { prices }\end{array}$ & $\begin{array}{l}\text { Unemploy- } \\
\text { ment }\end{array}$ & $\begin{array}{l}\text { Consumer } \\
\text { prices }\end{array}$ \\
\hline 1 & -0.11 & 0.00 & -0.11 & 0.02 \\
\hline 2 & -0.08 & 0.22 & -0.08 & 0.24 \\
\hline 3 & -0.04 & 0.18 & -0.04 & 0.16 \\
\hline 4 & -0.24 & 0.41 & -0.23 & 0.42 \\
\hline 5 & -0.29 & 0.35 & -0.29 & 0.35 \\
\hline 6 & -0.20 & 0.40 & -0.19 & 0.38 \\
\hline 9 & -0.17 & 0.60 & -0.01 & 0.59 \\
\hline 12 & -0.14 & 0.70 & -0.13 & 0.70 \\
\hline 24 & -0.30 & 0.91 & -0.25 & 0.91 \\
\hline Long-run & -0.31 & 1.00 & $\ldots .^{b}$ & 1.00 \\
\hline \multicolumn{5}{|l|}{ Significance level ${ }^{\mathrm{c}}$} \\
\hline Coefficient $^{d}$ & 0.55 & 0.05 & 0.77 & 0.05 \\
\hline \multirow[t]{2}{*}{ Sum of coefficients ${ }^{\mathrm{e}}$} & 0.27 & 0.002 & 0.90 & 0.003 \\
\hline & \multicolumn{2}{|c|}{ Equation 1} & \multicolumn{2}{|c|}{ Equation 2} \\
\hline \multicolumn{5}{|l|}{ Significance level ${ }^{\mathrm{c}}$} \\
\hline Homogeneity $\mathrm{f}$ & \multicolumn{2}{|c|}{0.004} & \multicolumn{2}{|c|}{0.003} \\
\hline Control dummies ${ }^{g}$ & \multicolumn{2}{|c|}{0.13} & \multicolumn{2}{|c|}{0.15} \\
\hline Sum of control dummies ${ }^{\mathrm{h}}$ & \multicolumn{2}{|c|}{0.81} & \multicolumn{2}{|c|}{0.78} \\
\hline
\end{tabular}

Source: Same as table 4a.

a. Dependent variable is the AHE index in nonmanufacturing industries, $w n$; independent variables are as defined in table $4 \mathrm{a}$.

b. See note $b$, table $4 a$.

c. See note b, table 1 .

d. See note $\mathrm{c}$, table 1 .

e. See note d, table 1 .

f. See note e, table 1 .

g. See note $f$, table 1 .

h. See note $\mathrm{g}$, table 1 .

the first difference restriction. The third is that the coefficients on unemployment, entered either as a first difference or as a level, are not significant either as a set or as a sum: in monthly data, there is no strong evidence of an effect of activity on wages.

Alternative Wage and Price Series. Using only one wage, hourly earnings in the private nonfarm sector, $w$, instead of its two components, $w m$ and $w n$, makes little difference to the estimated speed of adjustment of prices and of wages.

The wage variables used above are average hourly earnings, corrected 
for both overtime and interindustry shifts; the data exist for nonmanufacturing and for the private sector as a whole only since 1964. Thus, many economists, myself included, have estimated price equations for the postwar period using average hourly earnings in manufacturing, excluding overtime and either corrected $(\mathrm{wm})$ or not corrected (wmnc) for interindustry shifts.

The use of $w m n c$ instead of $w m$ and $w n$ makes a difference. When $w m n c$ is used instead of $w m$ and $w n$ in the price equation, the adjustment of prices to wages is only 15 percent complete after six months, 50 percent complete after a year; from table 1 , the corresponding numbers for the basic specification using $w m$ and $w n$ are 30 percent and 60 percent. The adjustment of wages to prices is roughly the same as before. While these results make the price adjustment appear slower, there is little question that the results obtained in the basic specification are to be preferred, as they use a wage measure that is free of interindustry shifts and thus is more appropriate. ${ }^{18}$ The sensitivity of the estimated speed to the wage measure used suggests, however, a potential explanation for the slow adjustment of prices to wages in the basic specification itself, one based on aggregation bias and measurement error. That explanation will be discussed in the next part of the paper.

The basic specification does not include prices of imported goods, although such goods are used in production and represent a portion of the goods included in personal consumption expenditures. Because a reliable monthly time series does not exist, I use the nominal tradeweighted exchange rate as a proxy. I find the long-run response of the price level to the nominal exchange rate in the price equation to be 8 percent and marginally significant. The shape of the dynamic effect of wages on prices is, however, unaffected. The exchange rate is statistically insignificant in the wage equations.

Subsample Stability. I have run the price and wage equations leaving out the periods from September 1972 through January 1974, January 1979 through December 1980, and January 1986 through May 1986-all periods of rapid input price changes, due to changes either in the price of food or in the price of fuel. The omission makes no substantive difference to the results. The dynamics of adjustment of prices and

18. The wage measure uncorrected for interindustry shifts shows, for example, a large drop during the General Motors strike, because wages in the automobile industry are higher than the average wage in manufacturing. 


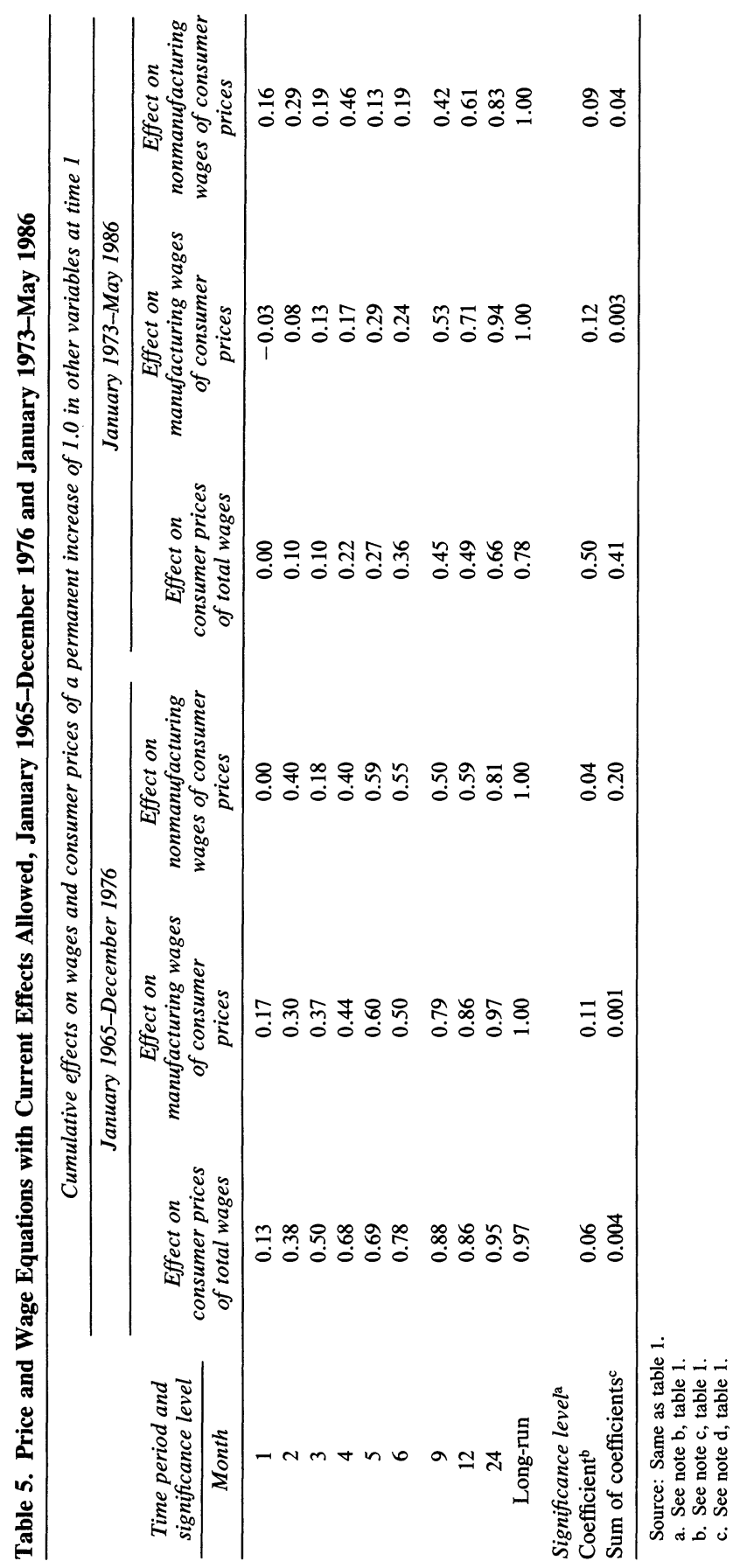


wages to one another are unchanged. The dynamic adjustment of prices to input prices is also substantially the same when those periods are left out.

I have also studied whether the wage and price equations were stable over time. The answer is mixed. Formal tests of subsample stability, cutting the sample at the end of 1972, 1975, or 1978, do not reject subsample stability, partly due to the large number of parameters of the model. The point estimates appear to differ in a systematic way across subsamples. Results of estimation over the periods January 1965 to December 1976 and January 1973 to May 1986(I use overlapping samples to have enough degrees of freedom and get reliable estimates) are reported in table 5. The adjustment of prices and wages to each other is slower in the second part of the sample, with the rough equality of speeds being preserved in each subsample. I do not explore further the issue of subsample stability in this paper and proceed with whole sample estimation and the caveat that the estimated coefficients and responses are means of coefficients and responses that have probably slowly changed during the sample.

\section{Evidence from Disaggregated Prices}

That the adjustment of the price level to an increase in nominal wages is only two-thirds complete after a year is surprising because many individual prices seem to adjust substantially faster. In order to get a better understanding of the wage and price dynamics of the economy, I turn next to a more disaggregated analysis.

\section{INDIVIDUAL AND AGGREGATE PRICE ADJUSTMENT}

There are three ways of reconciling my findings with the perception that many individual prices adjust rapidly. The first is simply that aggregate results reflect aggregation bias and that the adjustment of the price level to wages is in fact substantially faster than is suggested by the aggregate results. The second is that, because of interactions among price decisions, the cumulation of short lags at the individual level leads to longer lags for the aggregate price level. The third is that individual prices do not adjust quickly and that slow aggregate adjustment simply 
reflects slow individual adjustment. I examine these explanations in turn.

Aggregation Bias and Measurement Error. Aggregation conditions for the existence of such relations as "aggregate price and wage equations" are highly unlikely to be satisfied. This standard criticism of macroeconometrics may have particular relevance here. A plausible argument can be made that aggregation bias leads to estimated speeds of adjustment that are biased downwards and that the bias is more severe for the adjustment of prices to wages than of wages to prices.

The following example, which is inspired by the results obtained above using alternative wage measures, illustrates the argument. Assume that the price level is simply given by $p=w^{*}+e$, where $w^{*}$ is the nominal wage, so that there is no lag in the adjustment of prices to wages, no nominal price rigidity. Assume also that $w^{*}$ follows a random walk process, so that $w^{*}=w^{*}(-1)+v$, where $v$ is white noise, with variance $s_{v}^{2}$, and that the econometrician, instead of using $w^{*}$, uses instead a wage measure $w$, which is related to $w^{*}$ by $w=w^{*}+u$, where $u$ is white noise, with variance $s_{u}^{2}$. Under those assumptions, a regression of $p$ on current and lagged values of $w$ will give $p=(1-a)(1-a L)^{-1} w+z$, where $a=s_{u}^{2} /\left(s_{u}^{2}+s_{v}^{2}\right)$ and $z$ is a white noise disturbance term. The estimated mean lag will be equal to $\left(s_{u}^{2} / s_{v}^{2}\right)$. Thus, measurement error will lead to a spurious distributed lag relation and an upward bias in the estimated mean lag. The finding presented earlier that the estimated adjustment of prices is slower when a wage unadjusted for interindustry shifts is used can be explained along those lines.

In addition to showing how measurement error can lead to downward bias for the estimated speed of adjustment, the example suggests why the problem may be more serious in the price than in the wage equation. Individual wage earners have very similar consumption baskets and thus care about the same price index. Indeed, in formal indexation clauses, the same price index is nearly universally used. Thus, the price variable in each wage equation is the same for all wage earners. Price setters, on the other hand, face different wages, and those are not perfectly correlated. Thus the use of an aggregate wage measure may have effects similar to measurement error above. The fact that the significance level of wages in the price equation is lower than the significance level of prices in the wage equation is also consistent with that explanation.

Cumulation of Individual Lags. Under the previous explanation, aggregation leads to a spuriously slow estimated adjustment of the 
aggregate price to wages. Under a second explanation, the speed of adjustment is actually slower at the aggregate level than at the disaggregated level. The intuition behind this explanation is a simple one: individual prices depend not only on wages but also on other input prices, and while each price quickly adjusts to wages and to other input prices, the cumulation of small lags leads to longer lags at the aggregate level. ${ }^{19}$ Two examples will be useful in empirical work below. For simplicity, both are based on static expectations. I discuss below how the introduction of rational expectations and other modifications may affect the results.

The first example is that of vertical interactions through a chain of production, in which the final consumption good is produced through $n$ steps of production. Assume that the structure of price decisions is given by the following equations:

$$
\begin{aligned}
p_{1} & =w \\
p_{2} & =(1-a) p_{1}+a p_{1}(-1) \\
p_{i} & =(1-a) p_{i-1}+a p_{i-1}(-1) \\
p_{n} & =(1-a) p_{n-1}+a p_{n-1}(-1) .
\end{aligned}
$$

For simplicity, labor is used only in the first step. Thereafter, each price setter marks up by a constant fraction (constants are omitted for simplicity) over its input price, both current and lagged once. An interpretation of the lag structure is that each price is set partly on the basis of the current input price, partly on the expectation one period earlier of that price, with static expectations. Thus, at each step of the chain, the adjustment is complete within two periods, and the mean lag of adjustment is given by $a$. This set of relations implies the following final or aggregate price level equation:

$$
p_{n}=[(1-a)+a L]^{n} w .
$$

19. This old theme in Keynesian economics was recently restated by Robert J. Gordon, “Output Fluctuations and Gradual Price Adjustment,"' Journal of Economic Literature, vol. 19(June 1981), pp. 493-530. A related theme is that of lags in the process of production: if it takes time to produce goods, output prices may react with input prices with a lag. This proposition rests on theoretically weak grounds, as prices should be based on opportunity costs rather than purchase prices for inputs. It nevertheless may have some empirical validity; see Kenneth Coutts, Wynne Godley, and William Nordhaus, Industrial Pricing in the United Kingdom (Cambridge University Press, 1978). 
The equation, in turn, implies that the mean lag of the price level to the wage is given by an and is thus linearly increasing in the number of steps of pricing. The example generates slow aggregate adjustment of the final price, the price level, from quick individual adjustment.

The second example is based on horizontal interactions. Consider two price setters, producing a good under constant returns to scale, using as inputs both labor in proportion $(1-a)$ and the other producer's good in proportion $a$. Assume further that the two prices follow:

$$
\begin{aligned}
& p_{1}=a p_{2}(-1)+(1-a) w(-1), \text { and } \\
& p_{2}=a p_{1}(-1)+(1-a) w(-1),
\end{aligned}
$$

where the lags can again be explained as the result of price decisions one period in advance, based on static expectations of wages and input prices. In this case, the mean lag of the response to input prices and wages is 1.0 for each of the two prices. If the price level is defined as the weighted average of the two prices, its response to a shock in wages is slower. The mean lag of its response to wages is equal to $[1 /(1-a)]$. As the interaction between price decisions increases, the mean lag increases. A value of $a$ of 0.5 , for example, doubles the mean lag.

A minor generalization of the above example, which shows the effects of increasing the number of prices and thus increasing price interactions, is the following. Suppose that there are $n$ prices $p_{i}, i=1, \ldots, n$, and that each price follows:

$$
p_{i}=\sum_{j \neq i}^{n}(1 / n) p_{j}(-1)+(1 / n) w(-1), \quad i=1, \ldots, n .
$$

Each price depends with equal weights on all other prices and on the wage, again with a one-period lag. In this case, the mean lag of the response of the price level, defined as the average of all prices, to a shock in wages is simply equal to $n$. An increase in the number of prices therefore increases the mean lag.

Although these two examples are based on static expectations, cumulation effects are also likely to be present if price setters have rational expectations. However, in the simplest of rational expectations models, they are not. If all price decisions are assumed to be taken every period and if the assumption of static expectations is simply replaced by that of rational expectations based on information lagged one period 
(that is, lagged variables are replaced by expectations of current variables held as of one period earlier), lags will not cumulate. In both cases, any change in wages will be fully passed through after one period in the price level.

But as was first shown by John Taylor in the context of interactions between wage decisions, if decisions are not all taken at the same time, then the results above survive the introduction of rational expectations. ${ }^{20}$ If asynchronization is accepted as a fact, then the results of the two examples presented above are robust to the introduction of rational expectations. ${ }^{21}$ Elsewhere I have worked out the implications of the chain of production model with rational expectations, assuming that all price decisions were taken for two periods, with even-numbered prices being changed at even times and odd-numbered prices at odd times, clearly maximizing the degree of asynchronization in the economy. ${ }^{22}$ The results are qualitatively similar to those in the first example above, although the adjustment is faster. Assume, for example, that each price setter sets prices every two months, so that the average mean lag of the response of any producer to input prices is one month. Then, if there are ten steps to the chain, the mean lag of the response of the price level, the last price of the chain, to the wage is equal to 2.5 months.

When staggering of price decisions and rational expectations are introduced in the horizontal interaction example, it then has a structure identical to Taylor's model with the prices playing the role of the contract wages in Taylor. Thus the results are the same. The adjustment of the price level to wages is a gradual one, with the speed of adjustment being a decreasing function of the parameter $a$, the degree of interaction between price decisions.

20. Taylor, "Staggered Wage Setting."

21. A first reaction is that there are so many prices that they cannot all change at the same time. If price setters are free to choose the timing of their decisions and prefer to change prices together, the question still arises of why the timing distribution of price changes does not eventually become degenerate. Recent research on staggering includes L. Ball and D. Romer, "The Equilibrium and Optimal Timing of Price Decisions" (New York University, October 1986); L. Ball and S. Cecchetti, "Imperfect Information and Staggered Price Setting" (New York University, October 1986); Michael Parkin, "The Output-Inflation Trade-off When Prices Are Costly to Change," Journal of Political Economy, vol. 94 (February 1986), pp. 200-24.

22. Olivier J. Blanchard, "Price Asynchronization and Price Level Inertia, " in Rudiger Dornbusch and Mario Henrique Simonsen, eds, Inflation, Debt and Indexation (MIT Press, 1983), pp. 3-24. 
While staggering of decisions makes cumulation of lags likely even under rational expectations, Andrew Caplin and Daniel Spulber have constructed an important example where they do not. ${ }^{23}$ Their model can be recast in a form that resembles the model of horizontal interactions above. Suppose that there are $n$ price setters, $i=1, \ldots, n$, who, in the absence of costs of changing prices, would set their price equal to

$$
p_{i}^{*}=a p+(1-a) w,
$$

where $p$ is the price level and $w$ the nominal wage. ${ }^{24}$ The nominal wage is stochastic and nondecreasing in time. Price setters face costs of changing prices that lead them to change prices infrequently. Instead of changing prices at fixed intervals, as in the examples above, they adopt instead an $S s$ rule in which they change their nominal price $p_{i}$ whenever it becomes too low, that is, lower than $p_{i}^{*}$ by more than some fixed amount $s$. It is then readjusted upward by an amount $S$. If all price setters choose the same fixed $S s$ band, it is reasonable to assume that prices will be uniformly distributed over the interval $S s$. Thus, the economy exhibits both interactions between prices and staggering of price decisions. Caplin and Spulber show, however, that in that economy there is no aggregate nominal rigidity: the price level fully adjusts to the nominal money supply, and aggregate demand, which depends on real money balances, remains constant. The intuition for the result is simple: in response to a change in nominal money, only a few prices may be readjusted, but they are readjusted by a large amount. That adjustment is enough to lead to a change in the price level that is proportional to the change in nominal money.

In an economy that satisfied Caplin and Spulber's assumptions, an econometrician who estimated aggregate and disaggregated price equations would find no nominal rigidity. In the case of the price level, that is not surprising: as explained above, the price level adjusts fully and instantaneously to wage changes. More surprisingly, an econometrician who ran individual price equations, regressing individual prices on a distributed lag of the price level, would also find instantaneous adjustment, that is, a coefficient of one on the current price level and of zero

23. Andrew Caplin and Daniel Spulber, "Menu Costs and the Neutrality of Money," Quarterly Journal of Economics (forthcoming).

24. In the Caplin-Spulber specification, the wage is replaced by the money supply. The difference is unimportant here. 
on lagged values of the price level. The reasoning is as follows. As the price level $p$ moves with $w, p_{i}^{*}$ in equation 9 is equal to $p$, and the deviation from target for each individual price setter is just his relative price. After a sharp increase in the price level, for example, this relative price may be high if it has been readjusted or low if it has not. On average, it is impossible to tell, and the correlation between the relative price and inflation is equal to zero. Thus a regression of the relative price on current and past inflation would yield zero coefficients on inflation. Put another way, despite the fact that the nominal price is changed only infrequently, a regression of $p_{i}$ on current and lagged $p$ 's would lead to a coefficient of one on $p .^{25}$ (This result indicates that looking at the length of time between price decisions, as was done by Stigler and Kindahl and more recently by Carlton, is by itself not very useful for our purposes. ${ }^{26}$ What is important is not only the length of time but also the size of the adjustment and its determinants.)

To the extent that, in our data, the price level does not adjust instantaneously to wages, the assumptions of Caplin and Spulber are clearly not satisfied ${ }^{27}$ But the example serves as a caution that cumulation of lags is not necessarily the straightforward matter that it is under the assumption of fixed staggering.

Slow Individual Adjustment. The third potential explanation for the findings of the second section is that slow aggregate adjustment just reflects slow individual adjustment. Since, even under that hypothesis, there are horizontal and vertical interactions between price decisions, this explanation requires that individual price setters react at different speeds to changes in wages and to changes in other input prices. Namely, it requires slow adjustment to wages and fast adjustment to input prices.

One can think of two reasons why prices may adjust differently to wages and to other input prices. First, firms may have more market power in the labor market than they do in the markets for inputs. Many

25. Note that the econometrician is fitting a linear relation, whereas the $S s$ rule is nonlinear. There would be telltale signs that something is amiss, such as heteroskedasticity, for example.

26. George J. Stigler and James K. Kindahl, The Behavior of Industrial Prices (Columbia University Press, 1970); and Dennis W. Carlton, "The Rigidity of Prices," American Economic Review, vol. 76 (September 1986), pp. 637-58.

27. See Blanchard, "Why Does Money Affect Output?' for a discussion of how, even within Ss rule models, modifications of the Caplin and Spulber assumptions can lead to aggregate price rigidity. 
firms are wage setters as well as price setters. They are less likely to be price setters for input prices, especially for prices of crude materials that are determined in large part in competitive markets. Why this should lead to slower adjustment of prices to wages than to other input prices is, however, unclear.

Second, the stochastic processes for input prices and wages may differ in such a way as to lead to different expectational lags. A simple example, along the lines of the example of measurement error above, shows what is required. Suppose that prices are based on expectations of both input prices and wages based on information one period lagged. Suppose further that both input prices and wages are the sum of a random walk and a transitory white noise component, so that optimal forecasts take the form of Koyck lags on past values of the variables. Then, if the transitory component is less important for input prices than for wages, the estimated mean lag will be shorter for input prices than for wages. Prices of crude materials, which are traded in competitive markets, are indeed likely to have close to random-walk behavior. This is less likely to be the case in markets in which intertemporal arbitrage is less prevalent.

With these three hypotheses in mind, I look at the empirical evidence, first from the chain of prices from crude materials to finished goods and then from the set of wholesale prices within manufacturing.

\section{THE CHAIN OF PRODUCTION AND PRICING}

Specification of the Chain of Price Equations. The chain of price equations that I estimate is described in figure $3 .{ }^{28}$ It is determined by

28. I am not the first to estimate either a chain of price equations or a set of price equations within manufacturing. Joel Popkin, "Consumer and Wholesale Prices in a Model of Price Behavior by Stage of Processing," Review of Economics and Statistics, vol. 56 (November 1974), pp. 486-501; “The Integration of a System of Price and Quantity Statistics with Data on Related Variables," Review of Income and Wealth, vol. 24 (March 1978), pp. 25-39; “"The Business Cycle at Various Stages of Process," Journal of Business and Economic Statistics, vol. 2 (July 1984), pp. 215-23. Popkin goes further than I do here, by reordering manufacturing sectors so as to get a more detailed chain of production within manufacturing. The DRI model of the U.S. economy also has an extensive price system and includes equations corresponding to those of this paper. Those two previous approaches were extremely useful in indicating what the main characteristics of the data were. The approach I use differs in that it puts less structure on the dynamic relations and less emphasis on which variables other than prices and wages enter the equations. There is, however, no major discrepancy between my results and those in Popkin and DRI. 
Figure 3. The Chain of Pricing



the availability of data: what is available is the personal consumption deflator and a set of producer price indexes by stage of production.

Equation $\mathrm{C} 1$ ( $\mathrm{C}$ for chain) of the chain explains the personal consumption deflator $(p c)$ as a function of the finished consumer goods producer price index and nonmanufacturing wages. In addition to a time trend and seasonal dummies, the equation includes the finished consumer goods producer price index $(p 3)$, the wage index for services $(w s)$, the wage index for retail and wholesale trade (wtr), the wage index for finance and insurance $(w f)$, nonmanufacturing employment (enm), and the same set of wage-price control dummies as in the aggregate equations. 
The other equations explain the behavior of the producer price index (PPI), $p 3$. I decompose $p 3$ into two components, food ( $p 3 f)$ and nonfood ( $p 3 n f)$, which account for 40 percent and 60 percent of $p 3$, respectively. The reason for doing so is the fact that the response of $p 3 f$ and $p 3 n f$ to crude input prices may be quite different. The next two equations explain $p 3 n f$.

Equation $\mathrm{C} 2$ explains the finished nonfood consumption goods PPI, $p 3 n f$, as a function of the price of intermediate goods and manufacturing wages. The variables in the equation are, in addition to trend, seasonals, and wage-price control dummies, the nonfood intermediate goods PPI $(p 2 n f)$, the wage index for manufacturing $(w m)$, and manufacturing employment $(\mathrm{em})$.

Equation C3 explains, in turn, the nonfood intermediate goods PPI as a function of the price of crude materials and manufacturing wages. The variables in the equation are, in addition to trend, seasonals, and wageprice control dummies, the nonfood crude materials PPI $(p 1 n f)$, the wage index for manufacturing ( $\mathrm{wm}$ ), and manufacturing employment (em).

Finally, equation $\mathrm{C} 4$ explains the finished food component of the PPI as a function of the price of food inputs and manufacturing wages. The variables in the equation are, in addition to trend, seasonals, and wageprice control dummies, the foodstuffs component of the crude materials PPI $(p 1 f)$, the wage index for manufacturing $(w m)$, and manufacturing employment (em).

Econometric Issues. The general approach is the same as before, that of concentrating on the dynamic responses of prices to input prices and to wages. Thus, each equation is estimated as

$$
a(L) p_{i}=b(L) w_{i}+c(L) p_{j}+d(L) X+e_{i},
$$

where $p_{i}$ is the price to be explained in each equation, $w_{i}$ and $p_{j}$ are the appropriate wage(s) and input price, $X$ includes the other variables, and $e_{i}$ is a white noise disturbance.

The homogeneity restriction, which here takes the form $a(1)-b(1)$ $-c(1)=0$, is imposed throughout. There is again strong evidence in favor of a unit root in the underlying disturbance for each equation. All equations are therefore run in first differences. ${ }^{29}$ Based on preliminary

29. It is plausible - and particularly likely for equations $\mathrm{C} 2$ and $\mathrm{C} 3$ - that the source of nonstationarity in those equations is the same, related, for example, to productivity. This suggests the use of cointegrated estimation of the system of equations. I have not attempted it. 
tests for the order of the lag polynomials, ten lags are imposed in estimation of equation $\mathrm{C} 1$; seven lags, in the other equations. I have not explored whether the estimated dynamics are robust to alternative sets of $X$ variables.

The issues of simultaneity here differ from those in the previous part of the paper. The assumption that innovations in disturbances are uncorrelated across equations is much less likely to hold when estimating a set of price equations than when estimating an aggregate wage and an aggregate price equation. Innovations in equations $\mathrm{C} 2$ and $\mathrm{C} 3$ that describe price behavior for two types of goods (intermediate and finished) within the same sectors are, for example, quite likely to be correlated. The assumption that the right-hand side variables do not respond within the month is also unlikely to hold, especially early in the chain: in equation $\mathrm{C} 3$, for example, it is quite likely that the nonfood crude materials price $p 1 n f$, which is largely determined in spot markets, responds to changes in $p 2, p 3$, or $p c$ within the month.

The implication is that if current values of the variables are allowed to enter, the simultaneity bias is likely to be positive and more severe than it was for the aggregate price equation (the aggregate price equation is not affected by positive correlation across innovations along the chain). On the other hand, excluding all current variables is stronger than a similar exclusion in the aggregate price equation (which will be satisfied if any one of the equations has zero contemporaneous effects). I present estimation with and without current effects allowed. They are likely to give wider lower and upper bounds on the dynamic response than similar restrictions on the aggregate price equation.

I have also tried an instrumental variable approach, using the relative price of nonfood crude materials $(p 1 n f-p c)$ as an instrument for the current value of the corresponding nominal price $(p 1 n f)$ in equations $\mathrm{C} 2$ and $C 3$, using the relative price of food crude materials $(p 1 f-p c)$ as an instrument for the current value of $p 1 f$ in equation $\mathrm{C} 4$, and using the relative price of crude materials for further processing $(p 1-p c)$ as an instrument for the current value of $p 1$ in equation $C 1$. These instruments would be appropriate if crude materials prices responded one for one to innovations in the price level within the month, so that $(p 1-p c)$ represented exogenous changes in the crude materials price. The results implied a speed of adjustment roughly halfway between speeds obtained under current effects and no current effects assumptions. Results for equation $\mathrm{C} 2$ were, however, implausible, implying large contempora- 


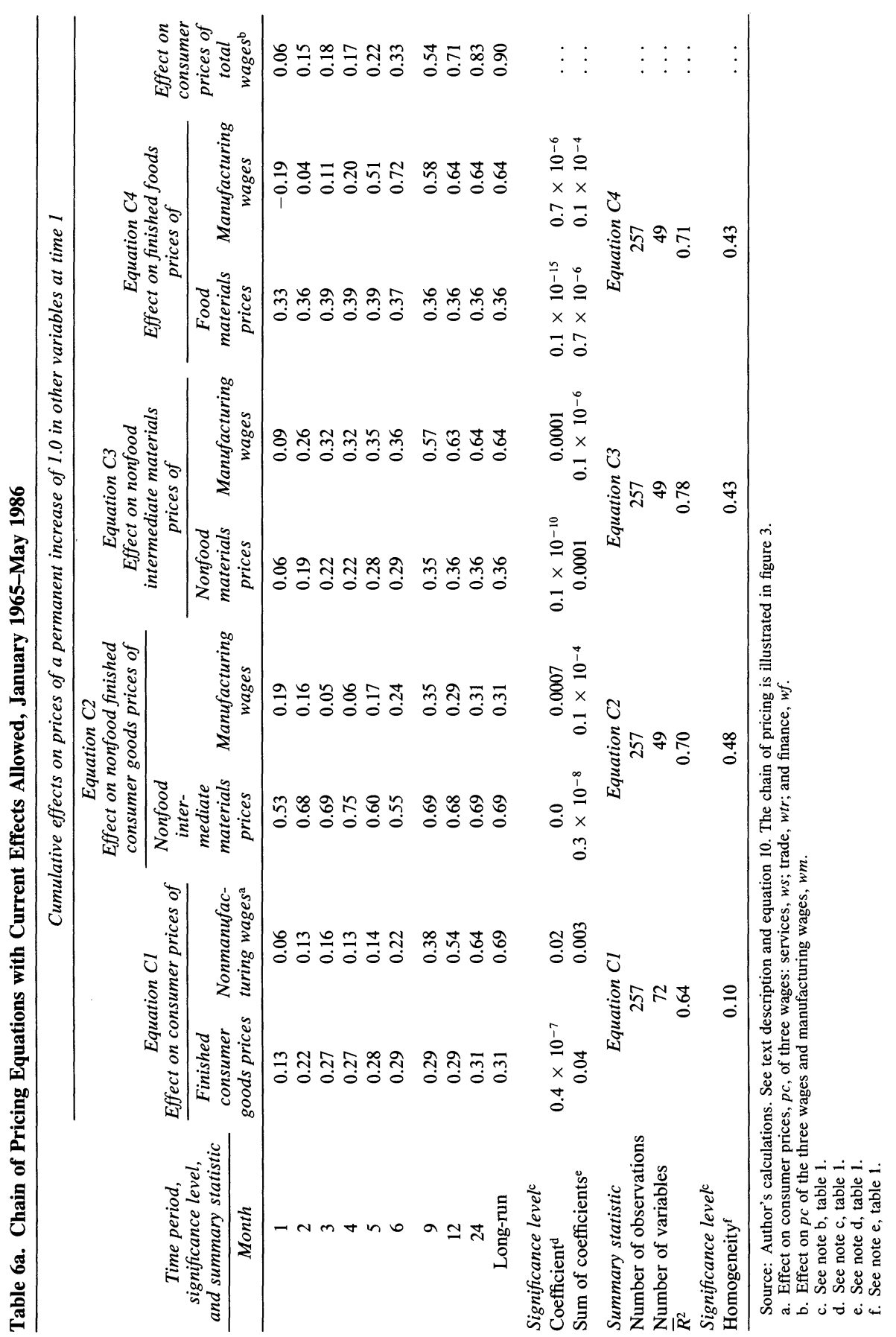


neous overshooting of $p 3 n f$ to $p 2 n f$, followed by a decrease over time. I concluded from that result that the identifying assumption was not appropriate, and I do not report the results further.

Results. Results are reported in table 6a in the case where current effects are allowed and in table $6 \mathrm{~b}$ for the case where they are not. Each table reports, for each equation, the estimated dynamic response of the price to the input price and to the wage(s), in addition to the significance levels associated with their coefficients as a set and as a sum. For equation $\mathrm{C} 1$, only the dynamic response to a common shock to the three wages ( $w f, w s$, and $w t r)$ is reported; collinearity leads to poor estimates of individual responses. Coefficients on employment and dynamic responses are not reported: in none of the four equations is the employment variable significant.

The last column of each table gives the dynamic response of $p c$ to a permanent shock in all wages $(w f, w s, w t r$, and $w m)$ implied by the system of estimated equations.

The two tables suggest two primary conclusions. The first is that each of the components of the chain is tightly estimated. Significance levels on wages and input prices in each equation are high, considerably higher than in the aggregate equation.

The second conclusion is that the results are consistent with those obtained when estimating the aggregate price equation. The important comparison here is between the dynamic response of the price to wages in the reduced form implied by the system of equations $\mathrm{C} 1$ to $\mathrm{C} 4$ in the last column of tables $6 \mathrm{a}$ and $6 \mathrm{~b}$, and the dynamic response in the estimated aggregate price equation in table 1 . When regressions that allow for current effects are compared, the implied reduced form has faster adjustment, especially after nine quarters, than the directly estimated price equation. When regressions that do not allow for current effects are compared, dynamic responses are very similar. Given the discussion above of the effects of simultaneity on system versus reduced-form estimation in this case, these results suggest little or no aggregation bias (there could obviously be aggregation bias at further levels of disaggregation). Even if the implied reduced-form response obtained allowing for current effects is taken as truth, my earlier conclusion that the speeds of adjustment of wages to prices and of prices to wages are similar remains accurate.

Tables $6 \mathrm{a}$ and $6 \mathrm{~b}$ give the following characterization of the adjustment of prices in individual equations. 


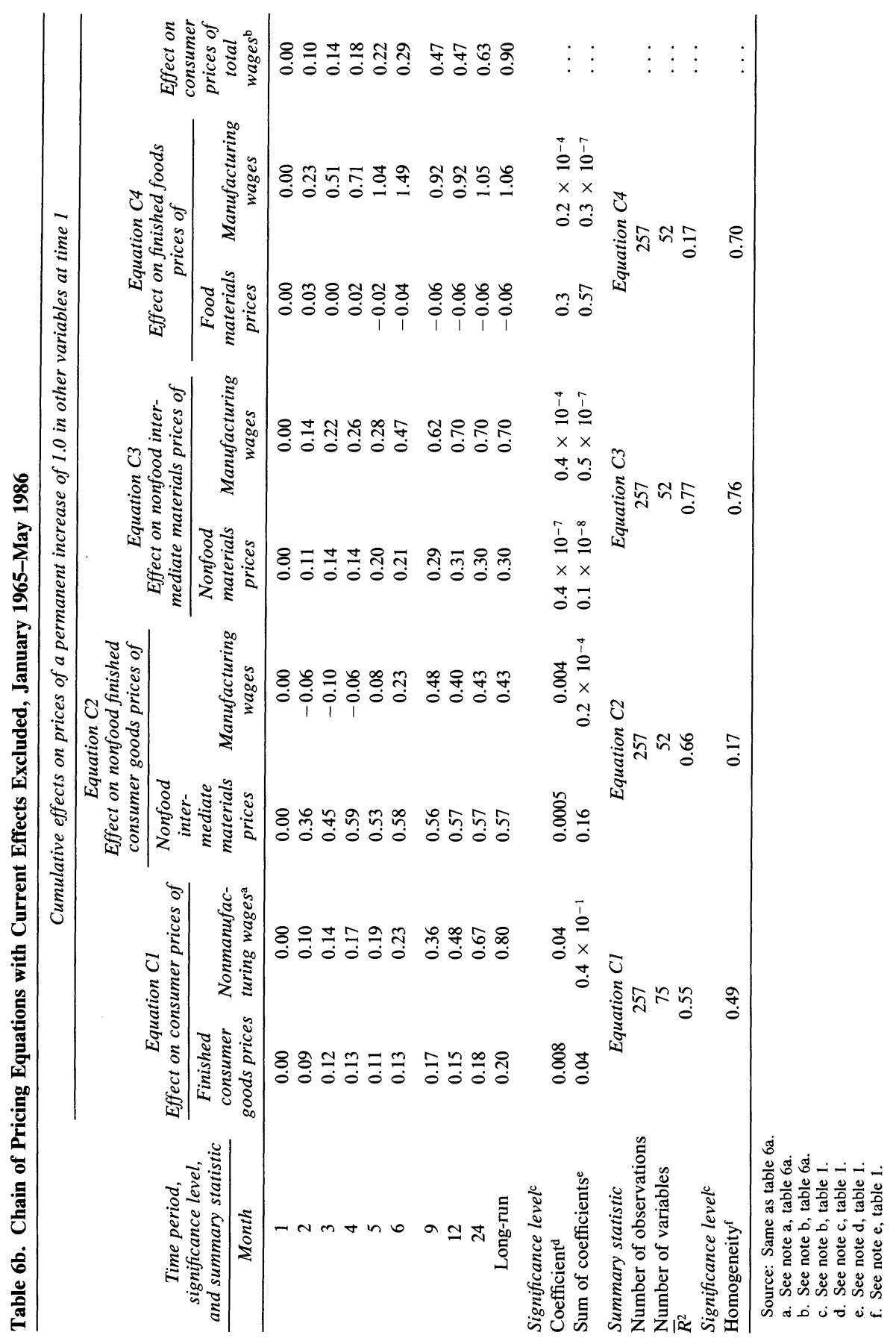


The personal consumption deflator adjusts fast to the wholesale price index and slowly to wages (the response to each of the three wages has standard errors too large to decide whether the dynamic response of $p c$ is different for the different wages). The adjustment to wages is only 45 percent (no current effect) to 55 percent (current effect) complete after nine months. The adjustment to the wholesale price index is substantially slower under the assumption of no current effects, but the current effects regression is probably more reliable. Simultaneity bias is likely to be less serious in this equation than in others, and the long-run responses to $p 3$ and $w$ obtained in table $6 \mathrm{a}$ are consistent with the share of labor in nonmanufacturing.

Within nonfood manufacturing, the adjustment to wages is faster than outside manufacturing, taking place largely within nine months. The adjustment of finished goods prices to intermediate goods prices is very quick, within a few months. The adjustment of intermediate goods prices to crude materials is slower, but still takes place largely within nine months.

Within processed foods manufacturing, the adjustment to the price of foodstuffs appears instantaneous. When no current effect is allowed, the price of foodstuff has no effect. The adjustment to wages is also fast, taking place in six months.

The results above suggest that aggregation is not the explanation for the results of estimation using aggregate data. They do not, however, speak strongly as to whether this is the result of cumulation of small lags or of slow individual adjustment.

Within nonmanufacturing, the faster response of the consumption deflator to input prices than to wages is not necessarily inconsistent with the cumulation hypothesis. Under that hypothesis the major determinant of the speed of the response to a particular input price is the number of pricing decisions through which it goes. If interactions within nonmanufacturing are mostly between services with the goods produced in manufacturing going through only a few steps of pricing, cumulation will lead to longer lags on wages than on the PPI. But while the response of $p c$ is not inconsistent with the cumulation hypothesis, it is no strong evidence in its favor. It is clearly more consistent with the third hypothesis developed earlier, that of slow adjustment to wages and fast adjustment to input prices at the individual level.

Within manufacturing, the faster adjustment of $p 3$ to $p 2$ than to $w m$ is 
difficult to reconcile with the cumulation hypothesis. The parallel adjustment of intermediate goods prices, $p 2 n f$, to crude materials and wages suggests that cumulation may be present there. More disaggregated evidence is needed to make stronger statements. I now look at evidence within manufacturing. ${ }^{30}$

\section{EVIDENCE FROM MANUFACTURING}

I first estimate price equations at the two-digit code level of disaggregation within manufacturing and then study the role of interactions between price decisions in explaining the behavior of the corresponding aggregate price index.

The Set and Specification of Price Equations. I examine the behavior of prices only in those manufacturing sectors that produce mostly either intermediate or final goods and for which data are available: ${ }^{31}$ textiles, with logarithm of price $p 1^{32}$ (4.6 percent); chemicals, $p 2$ (6.6 percent); rubber and plastics, $p 3$ (2.3 percent); pulp and paper, $p 4$ (8.1 percent); fabricated metals, $p 5$ (11.1 percent); machinery and equipment, $p 6$ (12.3 percent); and motor vehicles and equipment, $p 7$ (6.5 percent). Those seven sectors account for 52 percent of the aggregate PPI. Prices in the remaining ten sectors are taken as unexplained.

Each of the seven sectors uses labor, inputs from the seven sectors examined, and inputs from the other sectors.

It is neither feasible-because of insufficient degrees of freedomnor wise-because of collinearity between many input prices-to allow the prices of each input to enter with unconstrained distributed lags. Thus, I construct for each sector a composite input price, constructed

30. In what follows I look at evidence from manufacturing. Were the required data available, it would be best to study interactions in nonmanufacturing, both because the estimated adjustment to wages is slower and because nonmanufacturing accounts for a larger portion of the aggregate wage than does manufacturing.

31. The number in parentheses gives the December 1985 weight of the sector in the aggregate PPI in percent, which is a proxy for the relative importance of the sector in manufacturing. The weights used by the Bureau of Labor Statistics in computing the aggregate PPI are gross output rather than net output weights. Since 1978, BLS has been progressively introducing net output indexes. Those indexes, however, have existed for too short a time to be used here. Because classifications for prices, the input-output table, and wages all differ, a fair amount of data construction is needed here. It is described in the appendix.

32. Note that $p 1$ now denotes a different price from above. 
as a geometric average of all input prices, with weights being derived from an input-output table. ${ }^{33}$ Those weights are presented in table A-1 in the appendix. The main other variable in each price equation is the wage. I use for each sector the sector-specific average hourly earnings, excluding overtime.

The other variables in each price equation are a time trend, seasonal dummies, and the wage-price control dummies. I have not explored systematically the role of other variables. Specifications with either sector-specific indexes of industrial production or with aggregate manufacturing employment lead to nearly identical dynamic responses of prices to either wages or composite input prices. The results reported below are from specifications including no activity variable.

Econometric Issues. Each of the seven price equations is specified as:

$$
a(L) p i=b(L) p i c+c(L) w i+d(L) X+e i, \quad i=1, \ldots, 7,
$$

where $p i, p i c$, and $w i$ are the price, composite input price, and the wage in sector $i . X$ includes the time trend and the seasonal and wage-price control dummies; $e i$ is a white noise disturbance.

Because preliminary tests indicated that seven lags were sufficient for all sectors, seven lags were imposed in estimation. There is again strong evidence of a unit root in the underlying disturbance in each equation, so that all equations are run in first differences. The homogeneity restriction, which takes the form of $a(1)-b(1)-c(1)=0$, is also imposed in all equations.

As in the previous section, simultaneity is likely to be an issue in estimating this system of equations. Unobserved variables common to all sectors, such as taxes or productivity, are likely to imply positive correlation of innovations across equations. The fast estimated speeds of adjustment reported below suggest that there probably is also direct interaction between prices within the month. Simultaneity bias on wages from the response of wages to sectoral prices within the month is likely to be small. I therefore report the results from two alternative sets of regressions. The first allows for current effects of pic and wi on $p i$ in all

33. The assumption that the input price is a geometric rather than an arithmetic average, or equivalently that the technology is Cobb-Douglas rather than Leontieff in the respective inputs, is made for convenience. It implies the existence of an aggregate price equation of the same logarithmic form as the disaggregated ones. 


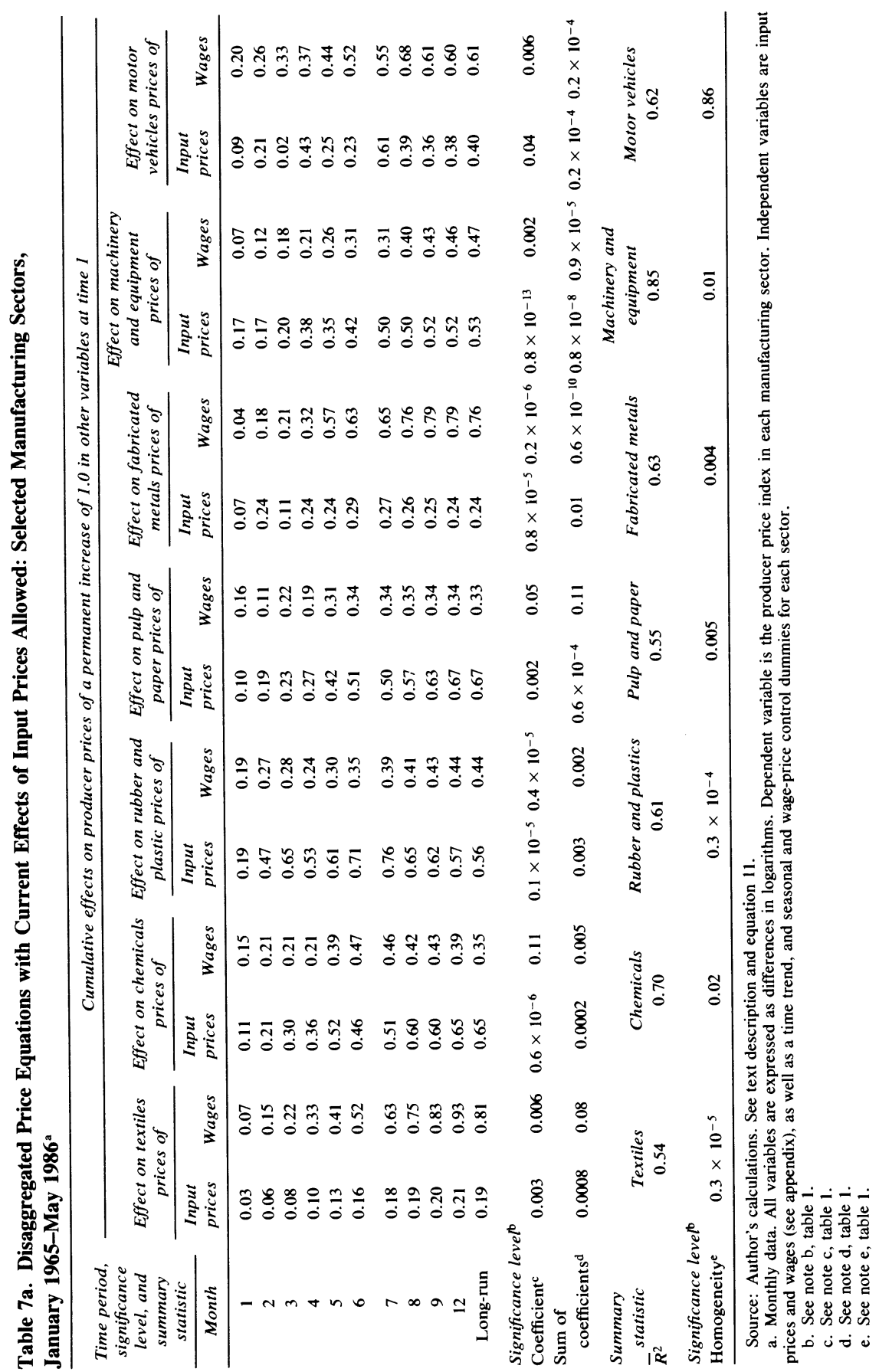


equations. It is not internally consistent: as in all equations the estimated contemporaneous effect of the composite input price is positive, the estimated system of equations implies that all prices $p i$ depend on all current disturbances, so that, in turn, the composite input prices and the disturbance terms are correlated. This set of regressions gives, however, an upper bound on the speed of adjustment of prices to input prices. The second allows for current effects of wi on pi, but assumes no current effects of pic on pi; this, in turn, gives a lower bound on the speed of adjustment.

Results. The results of estimation are reported in table $7 \mathrm{a}$ for the case where current effects of composite input prices are allowed and in table $7 \mathrm{~b}$ for the case where they are not.

The results give a clear picture of price adjustment in manufacturing. Coefficients on wages and composite input prices are highly significant in all equations, either as a set or as a sum. The dynamic responses are therefore tightly estimated. The treatment of simultaneity makes little difference to the results. I draw two main conclusions. First, the adjustment to both wages and composite input prices is fast. It takes, in many cases, only six months; in nearly all cases it is over after nine months. Second, the dynamic adjustment to input prices and to wages is similar, with little evidence in particular of faster adjustment to input prices than to wages.

I see both findings as strongly supportive of the cumulation hypothesis. The adjustment at this level of disaggregation is fast. The rough equality of speeds of adjustment to input prices and to wages, together with the fact that some of these input prices (those I explain) depend in turn on other input prices and wages, implies that there is cumulation of lags, slower adjustment at the aggregate level than at the disaggregated level.

The next question is whether the response to wages of the aggregate price index corresponding to those seven sectors is indeed slower than the individual responses and whether cumulation of lags can explain the difference.

Actual and Implied Reduced Forms, with and without Interactions. I first define the aggregate price index corresponding to the seven sectoral prices, then derive and compare the dynamic response of the price index to wages in three alternative reduced forms. The first is that obtained by direct estimation of the equation for the price index itself; I call it the actual reduced form. The second is the reduced form implied for the 


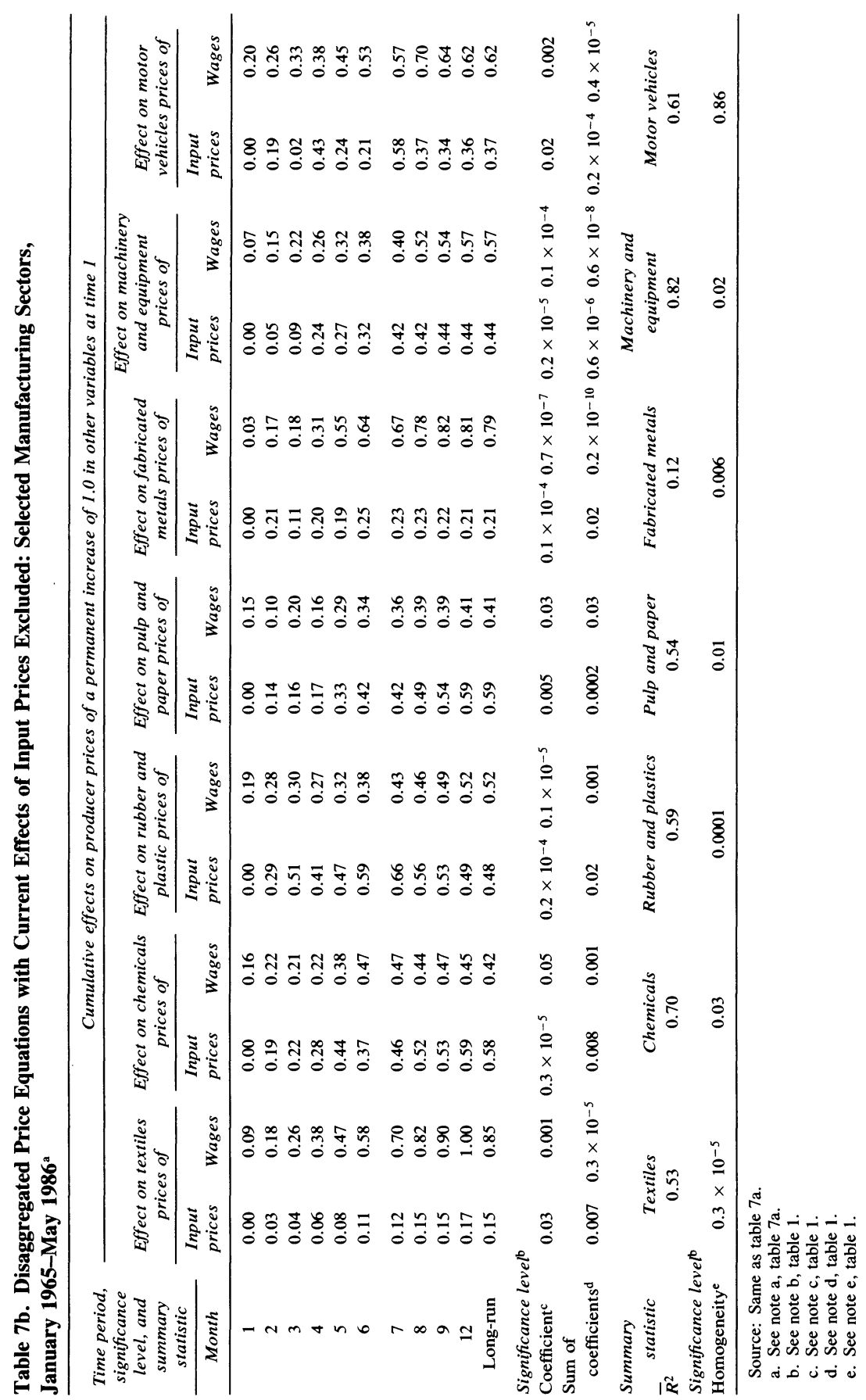


price index by the system of estimated sectoral equations: I call it the implied reduced form. The third is the reduced form that would obtain if there were no interactions among the seven sectors: I call it the nointeraction reduced form and defer its precise characterization.

As the first step, I define the price index associated with the sectoral prices as a geometric average of the sectoral prices, with weights proportional to their weights in the overall PPI but normalized to sum to 1.0. The logarithm of the price index is denoted by $p a$.

The reduced form of the system of equations given by equation 11 implies that $p a$ is a distributed lag of the wages in the seven sectors and of the prices of the outputs from sectors other than the seven. Estimation of such a reduced form, allowing for separate distributed lags on all those wages and prices, is infeasible. I therefore construct composite wage and input variables. The composite wage is a geometric average of sectoral wages, with weights obtained from the estimated system of sectoral equations. The weight on wage $w i$ is proportional to the longrun response of the aggregate price index to a permanent increase in $w i$ of 1.0; the weights are normalized to sum to 1.0. The logarithm of the wage index is denoted by $w a$. The composite input price is a geometric average of the prices of the sectors other than the seven, with weights proportional to the long-run responses of $p a$ to each input price implied by the estimated system of equations and normalized to sum to 1.0. The logarithm of the composite input price is denoted by pac.

The directly estimated reduced form has the form:

$$
a(L) p a=b(L) p a c(-1)+c(L) w a(-1)+d(L) X+e a,
$$

where $p a, p a c$, and $w a$ are, respectively, the price index, the corresponding composite input price index, and the corresponding wage index. $X$ includes the time trend, seasonals, and wage-price control dummies. It is estimated in the same way as the individual price equations, with seven lags, in first differences, and with the homogeneity restriction. It is estimated allowing both for current effects and for no current effects of input prices. The implied estimated dynamic response of prices to wages is presented in columns 1 and 4 of table 8 , under the two alternative assumptions about simultaneity. The response is presented, for ease of comparison with later results, as a cumulative percentage of the longrun response, so that it goes to 1.0 over time.

The dynamic response of the aggregate price index implied by the 
Table 8. Cumulative Response of the Manufacturing Price Index to Wages ${ }^{a}$

\begin{tabular}{|c|c|c|c|c|c|c|}
\hline \multirow[b]{2}{*}{ Month } & \multicolumn{3}{|c|}{$\begin{array}{l}\text { Current effects of } \\
\text { input prices allowed }\end{array}$} & \multicolumn{3}{|c|}{$\begin{array}{l}\text { Current effects of } \\
\text { input prices exluded }\end{array}$} \\
\hline & Estimated & Implied & $\begin{array}{l}\text { Implied: } \\
\text { no inter- } \\
\text { actions } \\
\text { case }\end{array}$ & Estimated & Implied & $\begin{array}{l}\text { Implied: } \\
\text { no inter- } \\
\text { actions } \\
\text { case }\end{array}$ \\
\hline 1 & 0.19 & 0.16 & 0.20 & 0.18 & 0.13 & 0.18 \\
\hline 2 & 0.22 & 0.26 & 0.32 & 0.22 & 0.23 & 0.30 \\
\hline 3 & 0.25 & 0.34 & 0.43 & 0.25 & 0.31 & 0.39 \\
\hline 4 & 0.33 & 0.41 & 0.50 & 0.31 & 0.38 & 0.46 \\
\hline 5 & 0.52 & 0.60 & 0.72 & 0.50 & 0.56 & 0.66 \\
\hline 6 & 0.54 & 0.70 & 0.84 & 0.53 & 0.62 & 0.80 \\
\hline 7 & 0.67 & 0.77 & 0.87 & 0.67 & 0.73 & 0.85 \\
\hline 8 & 0.89 & 0.90 & 1.00 & 0.88 & 0.88 & 1.00 \\
\hline 9 & 0.94 & 0.93 & 1.02 & 0.93 & 0.92 & 1.00 \\
\hline 12 & 1.00 & 1.00 & 1.03 & 1.00 & 1.00 & 1.00 \\
\hline Long-run & 1.00 & 1.00 & 1.00 & 1.00 & 1.00 & 1.00 \\
\hline
\end{tabular}

Source: Author's estimates based on equation 12.

a. Cumulative percentage of the long-run response of the input price index to a permanent increase in all wages of 1.0 at time 1.

system of estimated equations is obtained by increasing wages permanently by 1.0 in all seven equations and tracing the effect on prices and on the aggregate price index. This response is presented in columns 2 and 5 of table 8 , under the two alternative assumptions about simultaneity used in estimating the individual equations. Again, the response is presented as a cumulative percentage response.

Finally, columns 3 and 6 present the aggregate price index response that would take place in the absence of interactions. There is no compelling definition of the "no interaction" case. I simply take the system of estimated equations and simulate the effects of a shock to all wages, ignoring in each equation the terms that involve prices from the other six sectors. This has two effects. The first one is unimportant. Because I ignore the cross effects of prices, the size of the long-run response of the price index to the common wage shock is smaller: that is why I report cumulative percentage responses in all columns. The second and important one is that it eliminates the source of cumulation analyzed in the horizontal interaction example presented earlier, namely the interaction between prices across sectors. The dynamic response, reported in columns 3 and 6 , can be thought of as being roughly a 
weighted average of the dynamic responses of each sectoral price to its own wage, with weights corresponding to the relative importance of the sector in the aggregate price index.

What does table 8 show? A comparison of the implied and actual reduced-form responses (columns 1 and 2, or 4 and 5) tells whether the system of estimated disaggregated equations is able to replicate the dynamic response of the price index to wages estimated directly. A comparison of the results obtained when allowing for current effects suggests somewhat faster adjustment for the implied reduced form. But, as I have discussed earlier, the dynamic response given by the implied reduced form must be biased upwards. A comparison of the results obtained when current effects are not allowed suggests similar speeds of adjustment for the implied and actual reduced forms.

A comparison of the dynamic responses of the implied reduced forms with and without interactions shows the role of interactions among the seven sectors in creating slower adjustment of the aggregate price. Interactions lead to a slower adjustment, so that the adjustment of the price index is roughly a month behind the process of adjustment to each sectoral price. One might have expected the cumulation effect to be stronger. To understand why it is not, it is useful to return to the example of horizontal interactions among prices developed in the second section. In that example, the coefficient $a$, which measures the share of the other input in cost, is what determines the degree of cumulation. At the twodigit level, the empirical counterpart to coefficient $a$, which is the share of variable cost of each sector that is accounted for by purchases of inputs from the other six sectors, is not very large. Its average value is 25 percent, varying from 17 percent in fabricated metals to 48 percent for rubber and plastics. A value of $a$ of 25 percent would in the example of the second section increase the mean lag by 33 percent. The effect is a bit smaller here. More disaggregated data would show higher values of $a$ and more interactions and would lead to stronger cumulation effects. But building more disaggregated price equations is beyond the scope of this paper.

To conclude, the evidence from manufacturing supports the cumulation hypothesis. Disaggregated prices in manufacturing adjust quickly and at the same speed to both wages and input prices. Interactions between prices lead to a slower adjustment of the aggregate price index. 


\section{Implications and Conclusions}

Having documented the existence of nominal price rigidities and shown that they probably come, in large part, from cumulation of small lags at the individual level, I return to the implications of those findings for the effects of aggregate demand on output.

To do so, I use the model of fluctuations presented in the first part of the paper, but instead of using equations 1 and 2, I use their estimated counterparts. Given those equations and a simple specification of aggregate demand, I simulate the dynamic effects of an increase in the nominal money supply on output. To show the contributions of nominal price rigidity and nominal wage rigidity, I then redo the simulation, assuming instead instantaneous adjustment of prices to wages in the first case and instantaneous adjustment of wages to prices in the second case.

More specifically, let $\alpha(L), \mu_{m}(L), \mu_{n}(L)$, and $\mu_{p 1}(L)$ be the lag polynomials giving the distributed lag response of the price level to employment, the manufacturing wage, the nonmanufacturing wage, and the crude materials price index, obtained from estimation of the price equation in the basic specification, with current effects allowed in estimation. ${ }^{34}$ Let $\beta_{m}(L)$ and $\eta_{m}(L)$ be the lag polynomials giving the distributed lag response of the manufacturing wage to employment and to the price level, obtained from estimation of the manufacturing wage equation. Let, finally, $\beta_{n}(L)$ and $\eta_{n}(L)$ be the lag polynomials giving the corresponding distributed lag responses of the nonmanufacturing wage to employment and the price level. The polynomials $\alpha(L), \beta_{m}(L), \beta_{n}(L)$ characterize the dynamic effects of activity on prices and wages. The other polynomials characterize the dynamic interactions between prices and wages. I then simulate the following system:

$$
\begin{aligned}
p c & =\mu_{m}(L) w m+\mu_{n}(L) w n+\mu_{p 1}(L) p 1+\alpha(L) e, \\
w m & =\eta_{m}(L) p c+\beta_{m}(L) e, \\
w n & =\eta_{n}(L) p c+\beta_{n}(L) e,
\end{aligned}
$$

34. These polynomials are ratios of two polynomials, the lag polynomial associated with the variable divided by the lag polynomial associated with the price level. They are therefore of infinite order. Their coefficients are first differences of the coefficients reported in the cumulative responses of the price level to each of the variables in table 1. 


$$
\begin{aligned}
p 1 & =p c, \\
e & =(m-p c) .
\end{aligned}
$$

Equations 13, 14, and 15 are the estimated price and wage equations. (All the other variables appearing in the estimated price and wage equations will be assumed constant in the simulation and thus do not need to be included.) The system is closed by two simple equations. If the nominal crude materials price, $p 1$, was kept constant when nominal money increases, money would have long-run effects in the simulation. To avoid that, equation 16 simply assumes that the crude materials price, $p 1$, adjusts fully and instantaneously to movements in the price level. Equation 17 is an aggregate demand equation, which assumes that employment responds instantaneously to real money balances and with unit elasticity. The lack of dynamics on the demand side is obviously counterfactual; it has the shortcoming that the effects of an increase in money in the simulation will differ from the effects of an increase in money in the sample; it has the advantage for my purposes that the only dynamics in the system come from the supply side, the price and wage equations.

The first simulation, reported in the first three columns of table 9 , is of the effects of a permanent increase in the nominal money supply of 1.0 at time 1 on employment and on real wages in manufacturing and nonmanufacturing.

The second simulation, reported in the next three columns of the table, is of the effects of the same increase in nominal money, but removing nominal price rigidity, that is, assuming instantaneous adjustment of prices to wages in the price equation. Specifically, the second simulation replaces $\mu_{m}(L) w m$ and $\mu_{n}(L) w n$ in the price equation by $\mu_{m}(1) w m$ and $\mu_{n}(1) w n$, respectively.

The third simulation, reported in the last three columns, removes nominal wage rigidity instead and assumes instantaneous adjustment of both wages to the price level. Specifically, it replaces $\eta_{m}(L) p c$ and $\eta_{n}(L) p c$ in equations 14 and 15 by $\eta_{m}(1) p c$ and $\eta_{n}(1) p c$, respectively.

The crude nature of those simulations should be obvious. Before I go on and discuss the results, a few caveats are in order. The first is that the simulations rely on the estimates of both nominal and real rigidities obtained above. As I have repeatedly emphasized, I have more confidence in the estimates of nominal rigidities than in the estimates of the 


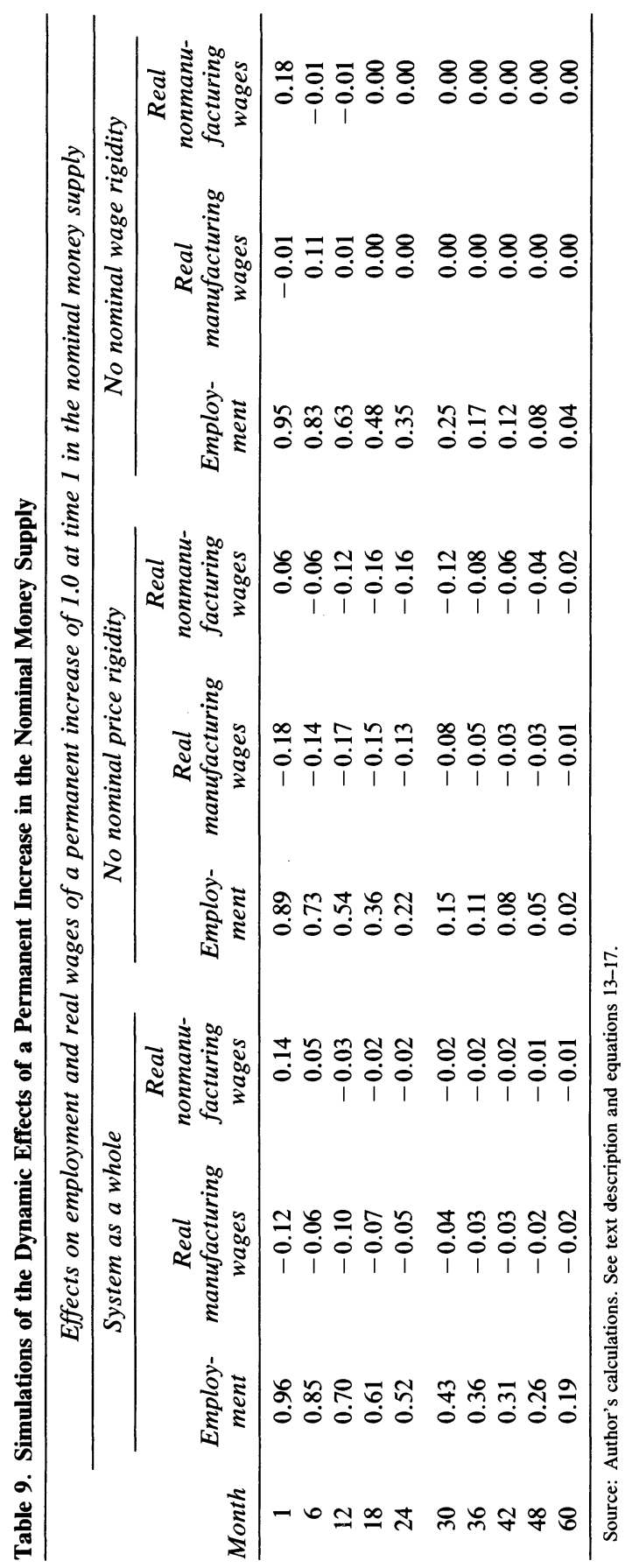


dynamic effects of the activity variable on prices and wages. If the use of monthly data hides effects of activity, the estimates of activity used in the simulation may be too small, and the simulation may overstate the length of the real effects of changes in the nominal money supply.

The two simulations that eliminate one or the other type of nominal rigidity show, in an accounting sense, the contributions of each of the two types of nominal rigidity to the adjustment process. They are, however, likely to be poor guides to what would happen if there were changes in price and wage setting that led to faster adjustment of either prices to wages or wages to prices. If, for example, complete wage indexation were introduced in the economy, the results might be quite different from those given in the third simulation. First, and least important, actual wage indexation would not lead, because of lags in the collection of prices and construction and use of the price index, to the instantaneous adjustment of wages to the price level assumed in the simulation. Second, while the simulation assumes that only the distributed lag of wages on prices is affected, changes in wage setting associated with wage indexation may also affect the distributed lag responses of wages to activity. Quite conceivably, they might also affect price-setting behavior and thus the distributed lag relations in the price equation.

With these remarks in mind, I now turn to the results. Given the estimated price and wage equations, weak effects of activity on prices and wages, together with the lags of adjustment of prices and wages to one another, lead to a slow adjustment of the price level to an increase in the nominal money supply: the adjustment of the price level is only 30 percent complete after a year, 50 percent complete after two years, 80 percent complete after four years. Equivalently, the real effects of nominal money on employment, which here is simply proportional to real money balances, are long lasting. Along the path of adjustment, there is little movement in both manufacturing and nonmanufacturing real wages.

When, in the second simulation, nominal price rigidity is removed, the adjustment of the price level to nominal money is substantially faster: the adjustment of the price level is 50 percent complete within a year and 80 percent complete within two years. Equivalently, the real effects of changes in the nominal money supply are over within two years. This clearly shows the importance of nominal price rigidity in the transmission mechanism of aggregate demand on output. 
The last simulation may, however, be more appropriate. In the simple models that have heretofore been used to study indexation, the conclusion has usually been that, under complete wage indexation, there would be no real effects of changes in the nominal money supply. ${ }^{35}$ The experiment performed in the last simulation, which is conceptually equivalent to introducing full indexation of wages, subject to the caveats listed above, shows that the presence of nominal price rigidity leaves room for substantial real effects of nominal money. With instantaneous adjustment of wages to prices, the adjustment of the price level is only 40 percent complete within a year, 65 percent complete within two years. The simulation again shows the importance of nominal price rigidity and suggests, in addition, that the effects of aggregate demand may differ much less across indexed and nonindexed economies than has been emphasized in the literature. ${ }^{36}$

\section{APPENDIX}

\section{Construction of Input Indexes}

THE TABLE needed to construct composite input indexes was constructed using the BEA's 1977 Input-Output (I-O) table. See "The Input-Output Structure of the U.S. Economy, 1977,' Survey of Current Business, vol. 64 (May 1984), pp. 42-84. I have used DRI's I-O table by PPI commodity group at the 2-digit level, except for fabricated metals, which required further disaggregation. The results are summarized in table A-1, which gives for each of the seven prices, $p 1$ to $p 7$, the contribution of each

35. Stanley Fischer, "Wage Indexation and Macroeconomic Stability," in Karl Brunner and Allan H. Meltzer, eds., Stabilization of the Domestic and International Economy, Carnegie Rochester Conference Series, vol. 5 (Amsterdam: North-Holland, 1977), pp. 107-47; Jo Anna Gray, "Wage Indexation: A Macroeconomic Approach," Journal of Monetary Economics, vol. 2 (April 1976), pp. 221-35.

36. This is for a given process for nominal money. To the extent, however, that indexed economies operate at higher rates of inflation than nonindexed ones, price setters may adjust their prices more often, and there may well be less nominal price rigidity in indexed economies. 
input to total input costs (the figures are rounded). The last line gives the percentage of total cost (expressed as a decimal) attributable to inputs other than labor or indirect taxes (this number is not used in estimation).

Table A-1. Input-Output Table ${ }^{a}$

\begin{tabular}{|c|c|c|c|c|c|c|c|}
\hline Inputs & $p 1$ & $p 2$ & p3 & $\begin{array}{c}\text { Output } \\
p 4\end{array}$ & $p 5$ & $p 6$ & $p 7$ \\
\hline Textiles $(p 1)$ & & . & 0.14 & 0.04 & & & 0.05 \\
\hline Chemicals $(p 2)$ & 0.31 & $\ldots$ & 0.62 & 0.29 & 0.16 & 0.06 & $\ldots$ \\
\hline Rubber and plastics ( $p 3)$ & $\ldots$ & 0.09 & $\ldots$ & 0.06 & 0.11 & 0.08 & 0.07 \\
\hline Pulp and paper $(p 4)$ & $\ldots$ & 0.10 & 0.08 & . . & $\ldots$ & $\ldots$ & 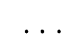 \\
\hline Fabricated metals ( $p 5)$ & $\ldots$ & 0.16 & 0.08 & 0.04 & $\ldots$ & 0.70 & 0.52 \\
\hline Machinery and equipment $(p 6)$ & 0.04 & 0.06 & $\ldots$ & . . & 0.16 & . . & $\ldots$ \\
\hline Transportation $(p 7)$ & . & . & $\cdots$ & . & $\cdots$ & $\cdots$ & $\cdots$ \\
\hline Farm products $(p 8)$ & 0.47 & & & . & .. & $\cdots$ & \\
\hline Processed foods $(p 9)$ & $\ldots$ & 0.04 & $\ldots$ & $\ldots$ & $\ldots$ & $\ldots$ & $\ldots$ \\
\hline Fuels and energy $(p 10)$ & 0.18 & 0.47 & 0.08 & 0.24 & 0.38 & 0.08 & 0.04 \\
\hline Lumber and wood $(p 11)$ & ... & . & $\ldots$ & 0.33 & $\ldots$ & $\ldots$ & ... \\
\hline Primary metals $(p 12)$ & . & . & $\ldots$ & . & 0.19 & . & $\ldots$ \\
\hline Others $(p 13)$ & $\ldots$ & 0.06 & $\ldots$ & . . & $\ldots$ & 0.08 & $\ldots$ \\
\hline Sum & 1.00 & 1.00 & 1.00 & 1.00 & 1.00 & 1.00 & \\
\hline Cost from nonlabor inputs & 0.41 & 0.50 & 0.54 & 0.48 & 0.33 & 0.50 & 0.59 \\
\hline
\end{tabular}

a. The composite input prices for each of the seven sectors are constructed by weighting input prices by their weight in each column. The wage variables are the logarithms of hourly earnings, excluding overtime for the following standard industrial classification codes: $w 1$, textiles (SIC 22); $w 2$, chemicals (28); w3, rubber and plastics (30); $w 4$, paper (26); $w 5$, fabricated metals (34); $w 6$, machinery (35 and 36); and $w 7$, motor vehicles (371). Blank cells in the table indicate small numbers that have been put equal to zero with the column sums renormalized to equal 1.0 . Some of the totals may not sum exactly, however, due to rounding. 


\section{Comments and Discussion}

Robert J. Gordon: The past five years have witnessed a welcome redirection in the microfoundations of Keynesian economics from the labor market to the product market as the central source of nominal rigidity. After a long period of emphasis on models in which wages are rigid and product prices play a purely passive role, set as a fixed markup over cost, economists have shifted their attention to the active behavior of monopolistically competitive price setters. It is easy to see why price rather than wage dynamics are at the heart of the business cycle. If cycles in the growth rate of nominal GNP are serially persistent, then if prices respond slowly to those nominal GNP changes, persistent cycles in the growth rate of real GNP must emerge by definition. In this sense, the gradual adjustment of prices is a necessary condition for business cycles, while sticky wages are not, since in principle profits could be sufficiently flexible to allow prices to mimic nominal GNP even if wages were sticky.

Olivier Blanchard's paper makes both theoretical and empirical contributions to our understanding of product markets. I find the theoretical analysis in the second section to be on the right track and complain only that it should go further. The main empirical conclusion, that aggregate wage and price adjustment speeds are similar, is familiar and unsurprising, but the reported absence of real activity effects (the flat Phillips curve) is highly dubious and is contradicted by a more careful look at the evidence. After a brief evaluation of Blanchard's theoretical framework, set forth in the second section of his paper, I will devote most of my comments to the aggregate evidence, set forth in the first section, which contains substantial overlap with my own previous research reported in past volumes of $B P E A$. 
The most important part of the second section is the hypothesis of cumulation of individual lags. It is most useful to contrast this approach with the Lucas-type imperfect-information model, in which an output response occurs because an information barrier prevents a firm from learning the current value of the aggregate price level that is necessary to decompose an observed local demand shock into its macroeconomic and microeconomic components. Such models have been rightly criticized, since in the real world there is no information barrier that inhibits agents from learning the very recent value of the consumer price index. The input-output table, as in Blanchard's "chain of production" model, destroys the fiction, basic to the Lucas approach, of a multiplicity of "representative agents" who produce a single homogeneous output under homogeneous production conditions. Such representative agents would never be in doubt about the reaction of other agents to an aggregate shock, since all firms are identical.

The essence of an input-output table is that firms are essentially different, producing heterogeneous products, yet are intertwined in a network of supplier-purchaser relations. In past writing I have endorsed the input-output approach as providing a persuasive explanation for the refusal of monopolistically competitive firms to adjust their prices to mimic the fluctuations of nominal aggregate demand:

Once decentralization and the multiplicity of supplier-producer relationships are recognized, no single firm can perform an action that would eliminate the aggregate business cycle. Each manager may recognize . . . that a recession in real output may be avoided by a uniform and instantaneous drop in all prices in exact proportion to a decline in nominal GNP. . . . Yet, he cannot see any way that he can "easily correct" the situation by his own isolated action, for he does not even know the identity of all the other agents in the input-output table of supplier-producer relationships. An isolated price decline by a single producer in exact proportion to a perceived decline in nominal demand will lead not to the elimination of business cycles but, rather, to bankruptcy if suppliers of intermediate inputs do not simultaneously adjust their prices. Each agent is caught in a "'prisoner's dilemma," aware of an aggregate inefficiency but without any private incentive to bear the enormous transaction cost of trying to correct it. ${ }^{1}$

A crucial element in the analysis of an input-output table model of gradual price adjustment is the formation of expectations of input costs in the context of an inference problem of untangling the aggregate and

1. Robert J. Gordon, "Output Fluctuations and Gradual Price Adjustment," Journal of Economic Literature, vol. 19 (June 1981), p. 525. 
local component of cost changes. With an input-output table, the notion of the local component is more complicated than in a Lucas representative-agent model, since the local component for the costs of a U.S. automaker include not just easily observable elements like the negotiations of the U.S. steelworkers union, but such obscure events as a shortage of electronic chips made in Taiwan due to a local power blackout. Faced with this complex inference problem, most firms may just wait by the mailbox to learn about cost increases rather than trying to anticipate them in advance, and this opens the wedge for Blanchard's equation 6, with its lagged price terms. But Blanchard needs to go deeper into the information structure of the firms looking backward and forward in the input-output table. Exactly why in equation 6 do firms look only at the current and lagged input price and pay no attention at all to the observable level of aggregate demand? And why do Blanchard's firms look only backward in the input-output table and not forward, ignoring the actual and expected demand of customers at the microeconomic level?

I turn now to Blanchard's aggregate wage and price equations. The two main findings are similar price and wage adjustment speeds and a flat Phillips curve. Blanchard's finding that the speed of adjustment of prices to wages is the same as or slower than the speed of adjustment of wages to prices is apparently supposed to surprise some people, who are referred to loosely as "the prevailing wisdom" and presumably think that wages adjust much more slowly than prices. Let me immediately withdraw myself as a candidate for inclusion in this discredited group. As long ago as 1975 I estimated mean lags for price adjustment to wages of 5.3 quarters, longer than anything Blanchard derives here. ${ }^{2}$

Tables 1 and 2 provide some alternative evidence on the two main findings of Blanchard's first section. The tables go beyond his finding that prices adjust as slowly as wages and show instead that prices adjust more slowly than wages. Yet they contradict his finding that the Phillips curve is flat. Three equations are shown in table 1-price change regressed on lagged wage change, wage change on lagged price change,

2. See Robert J. Gordon, "Can the Inflation of the 1970s Be Explained?" BPEA, 1:1977, table 2, pp. 260-61. Column 1 lists a mean lag of 4.8 quarters for an equation originally published in 1975 . The mean lag increases to 5.3 quarters in column 2 when reestimated with revised data. 
Table 1. Regression Equations of Prices on Lagged Wages, Wages on Lagged Prices, and Prices on Lagged Prices, 1965:1-1986:2a

\begin{tabular}{lcccc}
\hline & & \multicolumn{3}{c}{ Dependent variable } \\
\cline { 2 - 5 } $\begin{array}{l}\text { Independent variable } \\
\text { and summary statistic }\end{array}$ & $\begin{array}{c}\text { Lags } \\
\text { included }\end{array}$ & $\begin{array}{c}\text { Price } \\
(1)\end{array}$ & $\begin{array}{c}\text { Wage } \\
(2)\end{array}$ & $\begin{array}{c}\text { Price } \\
(3)\end{array}$ \\
\hline Wage & $1-24$ & $1.182^{\mathrm{b}}$ & $\ldots$ & $\ldots$ \\
& & $(10.9)$ & & $\ldots .920^{\mathrm{b}}$ \\
Price & $1-24$ & $\ldots$ & $1.059^{\mathrm{b}}$ \\
& & & $(9.2)$ & $(11.5)$ \\
Output ratio & $0-4$ & $0.229^{\mathrm{b}}$ & $0.359^{\mathrm{b}}$ & $0.279^{\mathrm{b}}$ \\
Productivity deviation & $0-1$ & -0.167 & $-0.356^{\mathrm{b}}$ & $-0.237^{\mathrm{c}}$ \\
Food-energy effect & $0-4$ & $1.443^{\mathrm{b}}$ & 0.181 & $1.099^{\mathrm{c}}$ \\
Relative import price & $0-3$ & $-0.156^{\mathrm{c}}$ & $0.148^{\mathrm{c}}$ & 0.038 \\
Relative CPI & $1-4$ & $0.467^{\mathrm{c}}$ & 0.137 & 0.076 \\
Effective minimum wage & $1-4$ & $0.055^{\mathrm{c}}$ & 0.049 & $0.079^{\mathrm{c}}$ \\
Nixon controls "on" & 0 & $-1.391^{\mathrm{c}}$ & $1.473^{\mathrm{c}}$ & -0.413 \\
Nixon controls "off" & 0 & $2.83^{\mathrm{b}}$ & -0.22 & 1.392 \\
Summary statistic & & & & \\
$\bar{R}^{2}$ & $\ldots$ & 0.901 & 0.816 & 0.871 \\
Standard error & $\ldots$ & 0.758 & 0.919 & 0.865 \\
\hline
\end{tabular}

Sources: Author's calculations. See text description and Robert J. Gordon, "Understanding Inflation in the 1980s," BPEA, 1:1985, pp. 263-99, table 2 and appendix A.

a. Quarterly data. The equation specified exactly matches table 2, column 4, of Gordon, "Understanding Inflation," except that tax variables are excluded and the sample period is changed to correspond to Blanchard's. Dependent variables are quarterly changes in natural logarithms. This and all other rate-of-change variables are expressed as annual rates, that is, as the change in the natural log times 400 . The output ratio is expressed as a level. The price variable is the GNP fixed-weight deflator; the wage variable is the private nonfarm average hourly earnings index adjusted for trend productivity growth. The output ratio is the ratio of real GNP to natural real GNP. Productivity deviation is output per hour in the nonfarm business sector (U.S. Bureau of Economic Analysis, Business Conditions Digest, series 358 ) less the trend rate of growth in productivity. The food-energy effect is calculated as the difference of the rate of change in the fixed-weight deflator for consumption and the rate of change in the fixed-weight deflator for consumption excluding food and energy. The relative import price is calculated as follows: for 1947-66, the difference of the rate of change in the fixed-weight deflator for imports and the rate of change in the GNP deflator; after 1966, the difference of the rate of change in the deflator for nonfood, nonfuel merchandise imports (constructed by Wing T. Woo) and the rate of change in the GNP deflator. Relative consumer prices is the rate of change in the consumer price index (Business Conditions Digest, series 320) minus the rate of change in the GNP deflator. The effective minimum wage is the nominal minimum wage (U.S. Social Security Administration, Social Security Bulletin) minus average hourly earnings, private nonfarm payrolls (Survey of Current Business). The controls "on" dummy variable is entered as 0.8 for the five quarters 1971:3-1972:3. The "off" variable is equal to 0.4 in 1974:2 and 1975:1 and to 1.6 in 1974:3 and 1974:4. The respective dummy variables sum to 4.0 rather than 1.0 because the dependent variable in each equation is a quarterly change expressed as an annual rate. All lag distributions are unconstrained. Numbers in parentheses are mean lags.

b. Sum of coefficients significant at the 1 percent level.

c. Sum of coefficients significant at the 5 percent level.

and a reduced-form that solves out the wage, regressing price change on lagged price change. The specification, chosen to be identical to my most recent $B P E A$ paper, differs from his in that I do not include the lagged dependent variable, except in column 3; I use different ' $X$ " variables; the wage and price variables are slightly different; and I use quarterly 


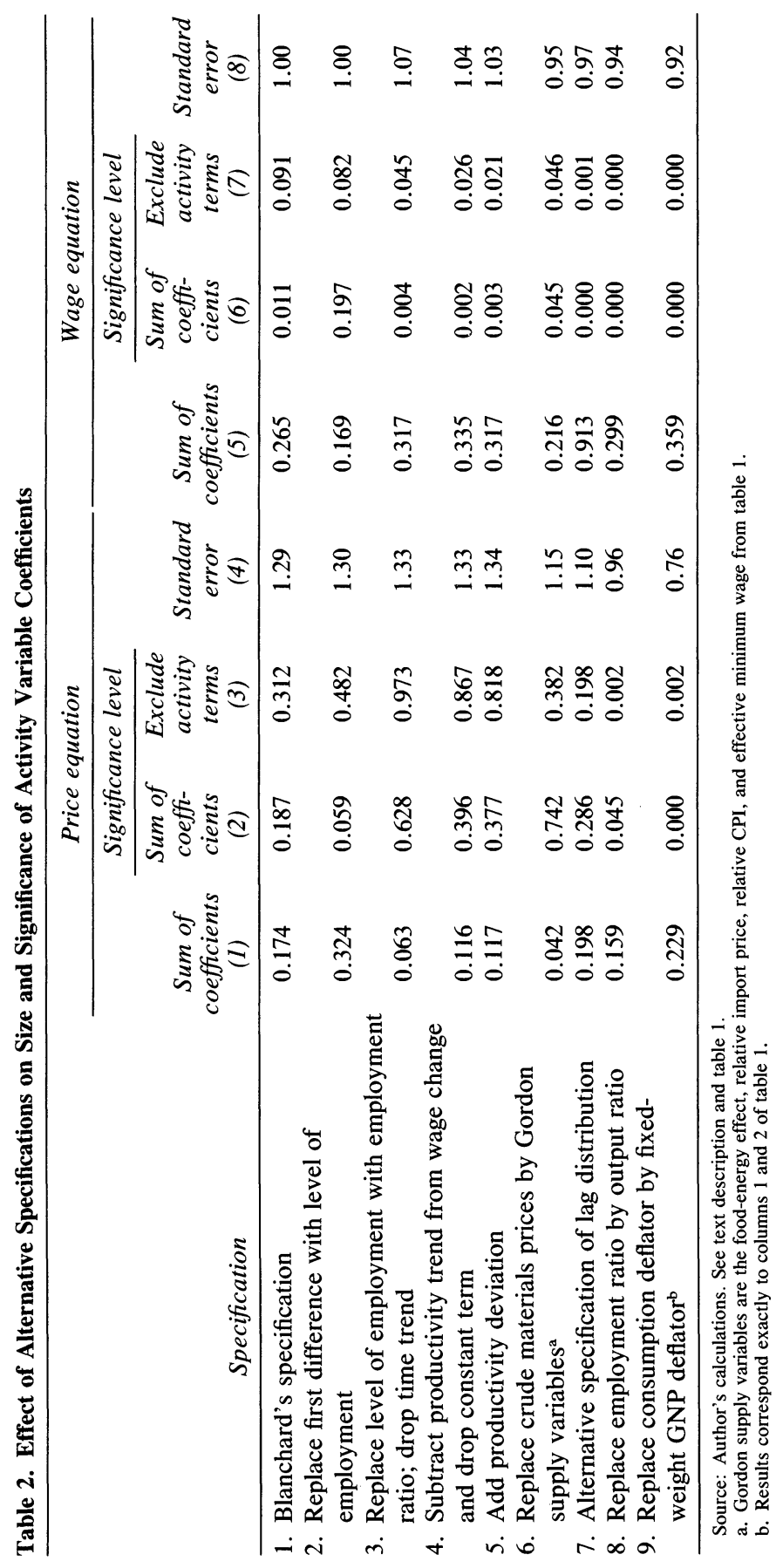


rather than monthly data. ${ }^{3}$ The sample period is identical to his. Space constraints prevent me from discussing the results of table 1 in detail, except insofar as they relate to Blanchard's main findings.

The first main point of interest is the set of mean lags, which are much longer than his and which show a slower response in the price equation than in the wage equation. The inclusion of twenty-four lagged wage and price terms in table 1 may seem surprising, yet an exclusion test decisively rejects the omission of lags thirteen through twenty-four in the two price equations (columns 1 and 3) at the 0.001 significance level. As further evidence of longer lags for prices than for wages, lags thirteen through twenty-four are insignificant in the wage equation.

Blanchard's simulations in the fourth section of his paper reveal an extraordinarily persistent business cycle. After a permanent increase of 1.0 in the nominal money supply, it takes fully twenty-four months before half of the initial real increase in employment disappears and fully sixty months before 80 percent disappears. In terms of Blanchard's basic model of equations $1-3$, this extreme degree of nominal inertia reflects not only the $\mu$ and $\eta$ coefficients of adjustment to lagged wages and prices, on which he places so much stress, but just as much the small and insignificant estimated coefficients on the $a$ and $b$ "activity" coefficients, on which he places much less emphasis. My results in table 1 are quite different, for I find highly significant sums of coefficients on the level of my activity variable, in contrast to Blanchard's small and insignificant sums of coefficients.

One possible source of this discrepancy, which I do not explore here, is the difference between Blanchard's use of monthly data and my use of quarterly data. To uncover other sources of difference using quarterly data, table 2 provides a step-by-step transition from Blanchard's data and specification to mine for the price and wage equations that correspond to columns 1 and 2 of table 1 , showing the steps that account for the conversion of the activity variable from limbo to statistical significance. Four statistics are shown: the sum of coefficients on the activity variable, the significance level of that sum, the significance level on a test that excludes all current and lagged activity terms from the equation, and the standard error of the fitted equation.

3. Robert J. Gordon, “Understanding Inflation in the 1980s," BPEA, 1:1985, pp. 26399. 
Line 1 shows an equation specified exactly like Blanchard's, in which the significance level of the activity variable is below (that is, better than) 0.05 only in column 6 (for the sum of coefficients in the wage equation), but not in columns 2,3 , or $7 .{ }^{4}$ Columns 2 and 3 show that only the last two steps (lines 8 and 9) yield a significant activity variable in the price equation. But in the wage equation the activity variable is significant by both the "sum" criterion in column 6 and the "exclude" criterion in column 7 in all versions from line 3 through line 8 . And in the final three lines for the wage equation, the significance level is extremely high, at the 0.001 level or better.

What are these transitions that resuscitate the activity variable? In line 2, I respecify Blanchard's employment variable as a level rather than as a first difference. This is a more general specification, since the estimated coefficients are free to reveal a first-difference effect (with positive followed by equal negative signs on successive lags). But it is not satisfactory to use a single time trend, as in line 2 , to convert the level of employment into a measure of demand pressure, since the time trend of employment varies over the sample period. Instead, in line 3, I drop the single time trend and instead detrend the employment variable by the "trends-through-benchmarks" method, using the same benchmarks as in my 1985 paper. This suffices to convert the activity variable to statistical significance in the wage equation, but not in the price equation.

The concept of wage change that matters for price setting is not raw unadjusted wage change, but rather net of the trend rate of productivity growth (that is, "trend unit labor cost"). Since productivity growth slowed down substantially after the early 1970 s, the role of the productivity growth trend cannot be captured by Blanchard's single constant term. In line 4 , the single constant term is dropped and replaced by a ratchet-like set of constants equal to the growth rate of productivity

4. There are two minor differences. My Nixon control dummies are used rather than his, since mine are specified for quarterly data and his for monthly data. Also, to simplify the presentation, I use a single wage index in the price equation, the adjusted private nonfarm hourly earnings index, instead of his separate manufacturing and nonmanufacturing wage indexes. Thus my quarterly version of Blanchard's wage and price change equations contains the following variables and lag lengths: wage change (one through four), price change (one through four), employment change (zero through four), crude materials price change (zero through four), my Nixon control dummies, a constant, and a time trend starting in 1964:1. 
between benchmarks. Line 5 adds the deviation of productivity growth from this trend to allow the concept of productivity growth that matters for price setting to be a weighted average of trend and actual productivity growth.

Up to line 5, the changes do not achieve a major improvement in the goodness of fit of the price and wage equations (shown in columns 4 and 8 ). But such an improvement does occur in line 6, which drops Blanchard's crude materials price index and inserts my supply-side variables (food-energy effect, relative import price, relative CPI, and effective minimum wage). The next shift, in line 7 , is to drop the lagged dependent variable (lags one through four) and stretch out the lag on the lagged wage variable in the price equation and lagged price variable in the wage equation to include lags one through twenty-four. Line 8 replaces the employment ratio by the "output ratio" (real GNP detrended by the same trend-through-benchmarks method). Finally, line 9 replaces Blanchard's consumption deflator by my fixed-weight GNP deflator.

In the end the activity variable is highly significant in both the price and wage equations. The decisive improvement in the price equation is to shift from employment to output; it is not surprising that output should be superior to employment as an indicator of demand pressure in product markets. The case for a sloped rather than flat Phillips curve in the wage equation seems extremely strong, once the basic misspecification of Blanchard's employment effect is corrected in lines 2 and 3 . It would be surprising if an analogous exercise could not revive the activity variable in monthly data.

Christopher A. Sims: What are price and wage equations? The issue crops up here and there peripherally in Blanchard's paper in the guise of the question of "simultaneity bias." But there is no explicit recognition of the fact that we cannot think clearly about the likely size of bias in a statistical procedure before settling on a definition, in terms of economic behavior, of the true parameters we are trying to estimate.

I have no objection to empirical work in which descriptive reducedform models are presented and interpretations of them are informal. Even work that purports to present a model with a unique behavioral interpretation is often usefully treated as a reduced-form modeling exercise, with results interpretable by various readers according to various theoretical frameworks. The disadvantage of work that does not 
explicitly discuss the real range of alternative interpretations of its statistical results is only that it may fail to present the statistics that are needed to make distinctions among interpretations.

At the start of the paper Blanchard gives a schematic complete model in which price and wage equations are to be thought of as embedded. In fact, in this section the wage and price equations have symmetric form, and the possibility of multiple interpretations of the same model equation is explicit. It might seem that the paper is going to treat its wage and price equations as part of a descriptive reduced form. But when Blanchard proceeds to estimation, wage and price equations become strongly asymmetric, in ways that are not justified by explicit economic reasoning.

Certainly, for example, if wage equations reflect wage bargaining or labor supply even in part, then cross-sectoral wage comparisons should be an important aspect of behavior. It seems hard to understand then why manufacturing and nonmanufacturing wage equations have only one lagged wage on the right-hand side, while the consumption price equation has both. The paper concludes that $w m$ and $w n$ respond quickly and strongly to $p c$. But suppose they actually respond quickly and strongly mainly to each other, with little response to $p c$ except insofar as it proxies for wages in the other sector? The paper as it is now presented does not allow us to tell whether this is what is going on.

Furthermore, all discussion of dynamics is in terms of conceptual experiments in which employment and a commodity price index are held constant, not just initially but indefinitely, while wages and consumer prices are disturbed. Since there is plausibly strong feedback between actual disturbances to consumption prices and wages on the one hand and the levels of employment and commodity prices on the other, one would like to see an explanation of why dynamics suppressing these feedbacks are interesting. The paper concludes that the response of $p c$ to wages is at least as sluggish as the response of $w m$ or $w n$ to $p c$. Suppose that in fact $p 1$, the commodity price variable, responds quickly and strongly to $w m$ and $w n$, so that actual movements in wages are followed quickly by corresponding movements in both $p 1$ and $p c$ ? This possibility is never explored in the paper, and under many reasonable hypotheses about behavior it would make a great difference to the interpretation.

Identification is not the only aspect of the model that is treated unconvincingly. All the data are logged and differenced, even though there is little a priori plausibility to the implications of this transformation. 
Modeling entirely in log differences implies that real wages, the ratio of wages in manufacturing to those in nonmanufacturing, the ratio of prices to commodity prices-all relative prices in fact and any ratios of them to employment-must be nonstationary. Putting the same point another way, the model rules out from the start long-run relationships among any of the variables, even among real variables. In a sample as short as this one, this could also tend to suppress relations among variables at business-cycle frequencies. It is unsatisfying, therefore, to have to rely entirely on Blanchard's assurances that the unrestricted versions of the equations appeared to him consistent with differencing of all variables. Recent theoretical results have shown definitively that there is no reason to suppose that distribution theory is simplified by preliminary differencing of data. The only reason for such preliminary differencing, even where the data accept it, is the possibility that it has a strong a priori appeal. But that does not seem to be the case here.

Blanchard discusses speed of response entirely in terms of percentage of eventual total response achieved in a given time. Suppose that $p c$ had shown a total response of 0.001 percent to a 1 percent rise in wages, and that this total response was complete within two months. Does this show a rapid response of prices to wages? Or does it instead show prices rigid, totally insensitive to wages? When homogeneity is not imposed, $p c$ shows a long-run elasticity to $w m+w n+p 1$ of 0.82 , while $w n$ shows an elasticity to $p c$ of only 0.66 and $w m$ shows an elasticity of 0.94 . One could argue that this shows that $w n$ is more rigid than price, which is in turn somewhat more rigid than wage.

I do not find Blanchard's argument for the homogeneity restriction convincing. (It rests on assuming that his equation 4 satisfies the homogeneity property and has a nonstationary disturbance. But it is the stationarity of the disturbance in equation 4 despite nonstationarity in the price level that makes homogeneity in equation 4 plausible.) In the manufacturing price equations it is rejected in six of seven industries, yet it is apparently still imposed. Imposing it implies that first differences of nominal variables are themselves nonstationary, but co-integrated.

Despite these criticisms of Blanchard's methods, I think we learn a considerable amount from his work. His work with disaggregated data, connecting the dynamics at finer disaggregations to those at higher levels of aggregation, is particularly valuable. He presents evidence that responses of output prices to input prices at low levels of aggregation in 
manufacturing are prompt and that cumulation of the small lags at low levels of aggregation could produce the longer lags observed at higher levels of aggregation. This is new insight from looking at a data set previously unexplored in this way; it should help to determine the development of economic theory in this field. It would be nice to know, however, how much the results depend on the arbitrary restrictions in this specification. Would they look the same if the strongly rejected homogeneity restrictions were dropped? Many economists would argue that price and wage setting at low levels of aggregation, besides responding strongly to sector-specific price and wage variables, are likely to respond more diffusely to a wide range of indicators of inflation and demand from outside the sector. Would a specification allowing for this produce different results?

Blanchard is undoubtedly right in claiming that there is no good case for treating aggregate wages as stickier than aggregate consumption prices. He has presented evidence that makes it plausible that aggregate stickiness is a cumulation of small frictions at low levels of aggregation. I think these conclusions would be more convincing if he had been more restrained in introducing ad hoc restrictions on the forms of his models.

\section{General Discussion}

In Robert Hall's opinion, it would have been more interesting to ask whether wages adjust fully to changes in prices than to ask, as Blanchard does, whether they adjust quickly. But the assumption of homogeneity in the equations for wage and price changes that is used throughout most of Blanchard's analysis precludes asking that question because it forces the constraint that wage and price changes, after some estimated lag, both react fully - that is, with an elasticity of 1.0 - to each other. In the past, Hall continued, Robert Gordon has taken the view that wages adjust slowly, but ultimately fully, to changes in prices. But Hall himself and others have taken the view that wages adjust quickly, but only partially, to changes in prices. Hall argued that the results Blanchard obtains when he does not impose homogeneity are quite consistent with that alternative view. Benjamin Friedman commented that whether the estimated speed with which wages and prices adjust to each other is considered fast or slow depends upon one's frame of reference. While 
an adjustment that is mostly complete after a year might sound fast, Blanchard's results also imply that wage and price adjustments to nominal shocks are only 20 to 40 percent complete after six months. The lags involved are quite long compared, for example, with the ten-month mean duration of postwar recessions. Thus, Friedman concluded, lags in wage or price adjustments cannot be ruled out as factors contributing to cyclical output movements.

Joseph Stiglitz noted that alternative interpretations of the observed degree of aggregate price and wage rigidity have different implications for understanding macroeconomic behavior. He gave as an example Blanchard's model in which prices in individual markets adjust quickly but, because of the cumulation of small lags, aggregate prices adjust sluggishly. In this case, the lagged response observed in aggregate prices would not have the usual interpretation given to sticky prices as a source of real rigidities, since individual markets are clearing quickly.

Considerable discussion focused on the interpretation of the small employment coefficients in both the price and the wage equations. Hall interpreted the small employment coefficient in the wage equation to imply a highly elastic schedule of labor supply and the small coefficient in the price equation to imply a high elasticity of labor demand with respect to the real wage. Equilibrium output thus would be virtually indeterminate in a model with flexible prices. Gordon disagreed, noting that standard Phillips curve equations, which are closely related to those Blanchard estimates, are best interpreted in a disequilibrium context, capturing what happens when agents are forced off their voluntary labor supply and labor demand curves. In this case, employment can change without requiring much if any change in wages, but that fact should not be interpreted to mean output is indeterminate. Martin Baily related Blanchard's findings to menu cost models that attribute large macroeconomic effects to costs that prevent the prompt adjustment of prices. The kind of wage and price stickiness that is most important for understanding macroeconomic behavior is the stickiness of wages and prices in response to aggregate demand. Such stickiness is a persistent finding in Blanchard's work, but cannot be thought of as arising from menu costs since they would also predict stickiness of wages and prices to each other, which Blanchard's results reject.

Bert Hickman noted that Blanchard's wage and price equations assume "bottom-up" wage and price determination, with changes in 
living costs and production costs showing up with a lag in wages and prices. He reasoned that there is also likely to be a "top-down" component to wage and price changes, with increased demand for final products pulling up the demand for intermediate products and, in the process, both wages and prices. He concluded that this sort of process may help account for the observed contemporaneous correlation between wages and prices.

Several participants raised questions concerning the specification of Blanchard's wage and price equations. Hendrik Houthakker argued that, while the manufacturing sector may be relatively homogeneous in its wage-setting behavior, the nonmanufacturing sector is quite diverse. Wage equations that separate sectors into those in which unions play an important role in wage setting from those in which unions are not important might be more informative than the equations separating manufacturing and nonmanufacturing sectors reported in the paper. Wayne Vroman agreed and observed that Phillips curve regressions for disaggregated unionized sectors (durables, nondurables, construction, mining and transportation) differ systematically from those fit for disaggregated nonunion sectors (wholesale trade; retail trade; finance, insurance, and real estate; and services). Unionized sector regressions yield large unemployment coefficients and lagged inflation coefficients that sum to near unity; in nonunion sector regressions, the effects of both demand and inflation on wages are much weaker. Houthakker also suggested that further disaggregation might be helpful in looking for interactions among manufacturing industries' wages and prices. For example, Blanchard assumes the prices of primary metals to be exogenous, but they are surely influenced by the market for fabricated metals. Edmund Phelps urged that more careful attention be given to the distinction between permanent and temporary change in the explanatory variables in Blanchard's wage and price equations. He also noted that changes in the cost of capital may be an important determinant of prices so that the real interest rate should be entered in the price equations. 